\title{
Synthesis of Poly(methacrylic acid-co-butyl acrylate) Grafted onto Functionalized Carbon Nanotube Nanocomposites for Drug Delivery
}

\author{
Josué A. Torres-Ávalos ${ }^{1}$, Leonardo R. Cajero-Zul ${ }^{1}$, Milton Vázquez-Lepe ${ }^{2}{ }^{\mathbb{D}}$, Fernando A. López-Dellamary ${ }^{3}$, \\ Antonio Martínez-Richa ${ }^{4}\left(\mathbb{D}\right.$, Karla A. Barrera-Rivera ${ }^{4}$, Francisco López-Serrano ${ }^{5}$ \\ and Sergio M. Nuño-Donlucas ${ }^{1, * \mathbb{D}}$ \\ check for \\ updates \\ 1 Departamento de Ingeniería Química, Universidad de Guadalajara, Guadalajara 44100, Mexico; \\ iq.josue.torres@gmail.com (J.A.T.-Á.); lcajero@yahoo.com.mx (L.R.C.-Z.) \\ 2 Departamento de Ingeniería de Proyectos, Universidad de Guadalajara, Zapopan 45100, Mexico; \\ milton.vazquez@cucei.udg.mx \\ 3 Departamento de Madera, Celulosa y Papel, Universidad de Guadalajara, Zapopan 45220, Mexico; \\ ferdellam@gmail.com \\ 4 Departamento de Química, Universidad de Guanajuato, Guanajuato 36050, Mexico; \\ richa28@msn.com (A.M.-R.); fionita@ugto.mx (K.A.B.-R.) \\ 5 Departamento de Ingeniería Química, Universidad Nacional Autónoma de Mexico, \\ Ciudad de Mexico 04510, Mexico; lopezserrano@unam.mx \\ * Correspondence: gigio@cencar.udg.mx
}

Citation: Torres-Ávalos, J.A.

Cajero-Zul, L.R.; Vázquez-Lepe, M. López-Dellamary, F.A.; MartínezRicha, A.; Barrera-Rivera, K.A.; López-Serrano, F.; Nuño-Donlucas, S.M. Synthesis of Poly(methacrylic acid-co-butyl acrylate) Grafted onto Functionalized Carbon Nanotube Nanocomposites for Drug Delivery. Polymers 2021, 13, 533.

https://doi.org/10.3390/ polym 13040533

Academic Editor: Yung-Sheng Yen

Received: 1 January 2021

Accepted: 7 February 2021

Published: 11 February 2021

Publisher's Note: MDPI stays neutral with regard to jurisdictional claims in published maps and institutional affiliations.

Copyright: (c) 2021 by the authors. Licensee MDPI, Basel, Switzerland. This article is an open access article distributed under the terms and conditions of the Creative Commons Attribution (CC BY) license (https:// creativecommons.org/licenses/by/ $4.0 /)$

\begin{abstract}
Design of a smart drug delivery system is a topic of current interest. Under this perspective, polymer nanocomposites (PNs) of butyl acrylate (BA), methacrylic acid (MAA), and functionalized carbon nanotubes $\left(\mathrm{CNTs}_{\mathrm{f}}\right)$ were synthesized by in situ emulsion polymerization (IEP). Carbon nanotubes were synthesized by chemical vapor deposition (CVD) and purified with steam. Purified CNTs were analyzed by FE-SEM and HR-TEM. CNTs $\mathrm{f}_{\mathrm{f}}$ contain acyl chloride groups attached to their surface. Purified and functionalized CNTs were studied by FT-IR and Raman spectroscopies. The synthesized nanocomposites were studied by XPS, ${ }^{13}$ C-NMR, and DSC. Anhydride groups link $\mathrm{CNTs}_{\mathrm{f}}$ to MAA-BA polymeric chains. The potentiality of the prepared nanocomposites, and of their pure polymer matrices to deliver hydrocortisone, was evaluated in vitro by UV-VIS spectroscopy. The relationship between the chemical structure of the synthesized nanocomposites, or their pure polymeric matrices, and their ability to release hydrocortisone was studied by FT-IR spectroscopy. The hydrocortisone release profile of some of the studied nanocomposites is driven by a change in the inter-associated to self-associated hydrogen bonds balance. The $\mathrm{CNTs}_{\mathrm{f}}$ used to prepare the studied nanocomposites act as hydrocortisone reservoirs.
\end{abstract}

Keywords: carbon nanotubes; nanocomposites; emulsion polymerization; methacrylic acid; nanocarriers; hydrogen bonds; hydrocortisone

\section{Introduction}

In recent years, polymer nanocomposites (PNs) have encompassed several growing fields of research. PNs can be applied in multiple areas such as medicine, aerospace, packaging, electronics, agriculture, and the automotive industry, among others [1,2]. In contrast to composite materials, PNs are characterized by at least one of their phases having a size in the order of the nanometer range. Typically, this fact has had a positive influence on the outstanding properties that these materials exhibit.

Among other nanomaterials used as nanofillers to prepare PNs, carbon nanotubes (CNTs) are a desirable option due to their exceptional properties. Although CNTs can be used in medicine, optics, electronics, and other diverse fields, they show drawbacks (such as insolubility, potential toxicity, and complicated manipulation) that should be overcome 
before their full application to an industrial level [3]. In this sense, the preparation of CNT-based PNs is a simple way to surpass these inherent difficulties.

As a consequence of their large area, CNTs have a high aspect ratio $(>1000)$, which favors their self-association. This fact complicates obtaining a homogeneous dispersion of CNTs in a polymer matrix. The challenge is not only to achieve the CNTs' exfoliation, but it is also necessary to avoid a secondary CNTs agglomeration after they are added to the polymer used as PNs' matrix. Several techniques have been developed in order to make the optimal dispersion of the CNTs possible [4].

Since it is necessary to prepare sufficient quantities of PNs (with a high grade of homogenization) for their commercial exploitation, there is a high level of interest to design a synthetic route that combines an optimal CNTs dispersion and a desirable amount of PNs produced. Chemical functionalization of CNTs, in situ polymerization, and emulsion polymerization are three techniques that can be used together in order to achieve this goal.

Chemical functionalization of CNTs is based on the attaching of a functional chemical group onto CNTs' surface by covalent bonds. This is developed on sites of the CNTs prone to react, either at their end caps or on their sidewalls. The functionalization reactions carried out specifically in $\mathrm{sp}^{3}$-hybridized defects, pentagon-heptagon pairs (Stone-Wales defects), and vacancies in the CNTs lattice [5]. Among the known methods to graft polymers onto CNTs, the "grafting from" method stands out. This is a consequence of their easy control and availability for conjugating a wide type of polymers onto CNTs, such as poly(acrylates), polystyrene, or hyperbranched polymers, to mention a few [6].

In situ polymerization is an adequate technique for synthesizing structured highperformance CNT-based PNs. In this technique, a monomer is polymerized in the presence of CNTs. In some cases, the combination of functionalized CNTs and an in situ polymerization method have made it possible to prepare well-dispersed nanocomposites [7].

Emulsion polymerization is the industrial technique most often used to synthesize polymers and is also one of the available techniques for preparing CNT-based PNs. However, up to now, there are few references in the literature that focus on the preparation of nanocomposites using this technique [8-10]. CNT-based PNs prepared by emulsion polymerization usually have better mechanical properties, high UV resistance, strong interfacial forces, and a better surface appearance than the ones observed in polymers synthesized by the same polymerization technique [9]. In situ emulsion polymerization (IEP) is an interesting approach for synthesizing CNT-based PNs. This is because several issues associated with the nanocomposites synthesis can be addressed simultaneously. The main advantage of preparing PNs by IEP (where water is the continuous phase) is the presence of water surrounding every forming polymer particle. Hence, heat is easily dissipated, there is no viscosity increase, and very importantly, there is a suitable condition for CNTs' exfoliation without causing any extensive thermal damage to polymer particles [10]. If a high grade of CNTs' exfoliation is achieved, the interfacial attachment between the CNTs and the polymeric matrix chains can be improved [11]. The key issue to overcome the problems associated with the synthesis of CNT-based PNs by IEP is to minimize the tendency of the CNTs to agglomerate. As CNTs have a natural propensity to self-agglomerate forming physical entanglements, achieving homogeneous CNT-based PNs is a difficult challenge [12]. The most successful strategy to avoid the CNTs' self-association by van der Waals forces is to achieve its chemical functionalization. This fact makes the synthesis of nanocomposites with functionalized CNTs by IEP very attractive from the chemical viewpoint.

To prepare CNT-based PNs with a specific chemical architecture following the "grafting from" strategy, the free-radical polymerization is a simple chemical route to exploit. An advantage of this technique is that it can be used to polymerize a large variety of monomers. Therefore, hydrophilic or hydrophobic polymers can be prepared by combining free-radical polymerization and IEP.

Poly (methacrylic acid) (PMAA) is a pH-sensitive polymer with a simple structure in contrast to other polymers, which have a complex structure and similar sensitivity [13]. The 
carboxylic acid groups contained in the methacrylic acid (MAA) units, in acidic conditions at $\mathrm{pH}$ lower than the $\mathrm{p} K_{\mathrm{a}}(\mathrm{pH}<4)$, are no ionized. Therefore, these moieties are able to form hydrogen bonds inwardly in the bulk of this ionic polymer. As a consequence, PMAA forms a collapsed structure. However, as the medium $\mathrm{pH}$ rises, the PMAA structure changes. In the range of a $\mathrm{pH}$ between 5 and 7, carboxylic acid groups are deprotonated. When the $\mathrm{pH}$ reaches values in the alkaline region $(\mathrm{pH}>7)$, PMAA chains attain an elongated rod-like conformation. These changes are reversible [14]. Therefore, PMAA is hydrophilic at $\mathrm{pH} 7.4$ (typical $\mathrm{pH}$ of the human blood) and hydrophobic at low $\mathrm{pH}$ (around 1-2). Based on its properties, PMAA can be used to create an oral drug delivery system [15]. CNTs functionalized with PMAA can be used as interesting drug delivery nanocomposites sensitive to the $\mathrm{pH}$ of the surrounding medium. The protonated/deprotonated behavior of PMAA implies a strong change in polarity. This fact, along with the repulsive Coulomb interactions, is of high relevance. Due to the formation of deprotonated structure, if the PMAA is mixed or attached to a hydrophobic polymer, the preparation of a drug delivery system can be favored.

Butyl acrylate (BA) is a hydrophobic monomer and is used as a "soft monomer." Some of its copolymers have been reported as biocompatible [16]. The low-temperature properties and toughness of copolymers prepared with BA can be improved, based on the soft nature of this monomer. The BA copolymers' properties can be tailored to meet specific requirements.

Although the synthesis of the MAA-BA copolymer has been reported elsewhere [17], its practical applications have not been studied extensively. In this respect, its possible use as a drug delivery system is of special interest.

The development of new drug delivery systems seeks to enhance drug targeting. At the same time, improving drug efficiency and reducing the toxic effects is a desirable goal. For this, the design of drug transporters is a crucial factor, because they have a decisive influence on drug delivery and drug interaction [18]. CNTs grafted onto biopolymers have a high potential for use in the drug delivery field [19]. However, its possible toxicity is an unsolved problem. On the one hand, there are reports that point out that CNTs produce adverse effects on living tissues $[20,21]$. On the other hand, reports regarding the safe use of CNTs for humans have been presented elsewhere [22]; in particular, it is reported that functionalized CNTs have shown minor toxicity [23]. PMAA was the first polymethacrylate used in oral dosage form for drug delivery [24]. Two copolymers of PMAA have been applied with gastrointestinal (GI) tract targeting for drug delivery: (i) poly(methacrylic acid-co-ethyl acrylate) dissolved in duodenum at $\mathrm{pH}>5.5$, and (ii) poly(methacrylic acid-co-methyl methacrylate) dissolved in jejunum at $\mathrm{pH}>6.0$ or in colon at $\mathrm{pH}>7.0$ [25]. These copolymers are supplied under the trade name Eudragit for pharmaceutical applications. Broad release capabilities can be achieved if the ratio of monomers used to prepare MAA-based copolymers is changed.

Among other drugs, hydrocortisone (11 $\beta, 17 \alpha, 21$-trihydroxypregn-4-ene-3,20-dione) is of particular interest due to its anti-inflammatory action. Hydrocortisone is an antiinflammatory and hydrophobic drug that can be administered orally, topically, or by injection. This drug is widely used for the treatment of various diseases, such as certain types of allergies, arthritis, and asthma [26]. In addition, hydrocortisone has been used as treatment for several types of cancers, such as adrenocortical cancer [27], prostate cancer [28], leukemia [29], or lymphoma [30], among others.

The aim of this work is to prepare a $\mathrm{pH}$-sensitivity novel drug delivery system synthesized from PNs with functionalized carbon nanotubes $\left(\mathrm{CNTs}_{\mathrm{f}}\right)$ as a reinforcing agent, and an MAA-BA copolymer as a polymeric matrix. To the best of our knowledge, the synthesis of the nanocomposites mentioned, following the chemical route presented here, has not been previously explored. The synthesis was carried out by IEP, under free-radical polymerization using water as continuous media, through a "grafting from" approach. In contrast to previously published in other works for drug delivery systems prepared with PMAA [24,25], in this work, BA co-monomer and functionalized CNTs were used in the 
preparation. It is expected that the last two components of the studied PNs increase their capacity to deliver drugs. The prepared nanocomposites contain a $\mathrm{pH}$-sensitive copolymer (poly(MAA-co-BA)) attached to functionalized CNTs by a hydrolytically cleavable bond (anhydride groups). The morphology of the studied nanocomposites depends on the BA/MAA wt.\% ratio, as well as the type and content of $\mathrm{CNTs}_{\mathrm{f}}$ used. As a model for drug delivery study, their capacity to deliver hydrocortisone was evaluated. The presence of CNTs is a crucial factor in the ability of studied PNs to release hydrocortisone. The synthesized PNs could be used as smart nano-carriers with a targeted drugs' release capast.

\section{Experimental}

\subsection{Materials and Methods}

Alumina boat was acquired from Alfa Aesar. Potassium persulfate (KPS) (reagent grade), hydrochloric acid ACS reagent $37 \%$, and nitric acid ACS reagent $70 \%$ were purchased from Fermont México. Iron(III) nitrate nonahydrate $\mathrm{Fe}\left(\mathrm{NO}_{3}\right)_{3} \cdot 9 \mathrm{H}_{2} \mathrm{O}>98 \%$, dichloromethane ACS reagent $>99 \%$, acetone ACS reagent > 99\%, methanol ACS reagent > $99 \%$, sodium carbonate $0.1 \mathrm{~N}$, hydrochloric acid $0.1 \mathrm{~N}$, and sodium hydroxide $0.1 \mathrm{~N}$ were

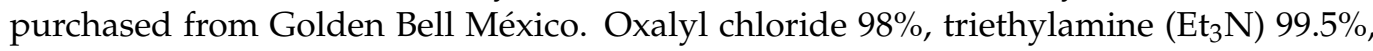
ethyl alcohol absolute $99.8 \%$, potassium bromide FT-IR grade $>99 \%$, tetrahydrofuran (THF) anhydrous $>99 \%$, lithium hydride $95 \%$, aluminum $99.9 \%$, butyl acrylate $>99 \%$, sodium dodecyl sulfate $98 \%$, methacrylic acid $99 \%$, and hydrocortisone $98 \%$ were purchased from Aldrich. Nitrogen gas and argon gas were acquired from Praxair México. Double-distilled water was purchased from "Productos Selectropura" México. Potassium biphthalate buffer $\mathrm{pH} 5$ was purchased from Jalmek and used as received.

\subsection{Synthesis and Purification of CNTs}

CNTs were prepared via chemical vapor deposition (CVD) following an experimental procedure reported by our group elsewhere [31]. CNTs were purified with overheated steam. For this, $2 \mathrm{~g}$ of unpurified CNTs, wrapped in steel mesh, were placed in a quartz tube $(1.3 \mathrm{~cm}$ i.d. and $25.4 \mathrm{~cm}$ long). Then, the overheated steam (at $873.15 \mathrm{~K}$ and $85.3 \mathrm{MPa}$ ) was fed for $3 \mathrm{~h}$. This procedure was repeated twice. Purified CNTs were named CNTsp.

\subsection{Functionalization of CNTs}

$\mathrm{CNTs}_{\mathrm{p}}$ were functionalized to insert methacrylic acid (MAA) molecules onto its surface before their use in the nanocomposites preparation, following an experimental procedure of several steps (the sequence is depicted in Scheme 1): (i) CNTs pere partially oxidized to insert hydroxyl, carboxyl, and carbonyl groups onto their walls. The product, partially oxidized CNTs, was named $\mathrm{CNTs}_{\mathrm{o}}$. (ii) To increase the amount of hydroxyl groups, a reduction of carboxyl groups was carried out through a treatment of $\mathrm{CNTs}_{\mathrm{O}}$, with lithium aluminum hydride. The product was named $\mathrm{CNTs}_{\mathrm{r}}$. (iii) $\mathrm{CNTs}_{\mathrm{o}}$ and $\mathrm{CNTs}_{\mathrm{r}}$ were functionalized separately to insert acyl chloride groups onto their walls. For this, both types of CNTs were treated with oxalyl chloride $(\mathrm{OxCl})$. The products were named $\mathrm{CNTs}_{\mathrm{o}-\mathrm{OCl}}$ and $\mathrm{CNTs}_{\mathrm{r}-\mathrm{OCl}}$. (iv) $\mathrm{CNTs}_{\mathrm{o}-\mathrm{OCl}}$ and $\mathrm{CNTs}_{\mathrm{r}-\mathrm{OCl}}$ reacted separately with MAA molecules. Two types of products were obtained separately and named $\mathrm{CNTs}_{\text {o-OCl-MAA }}$ and $\mathrm{CNTs}_{\mathrm{r}-\mathrm{OCl}-\mathrm{MAA}}$. 

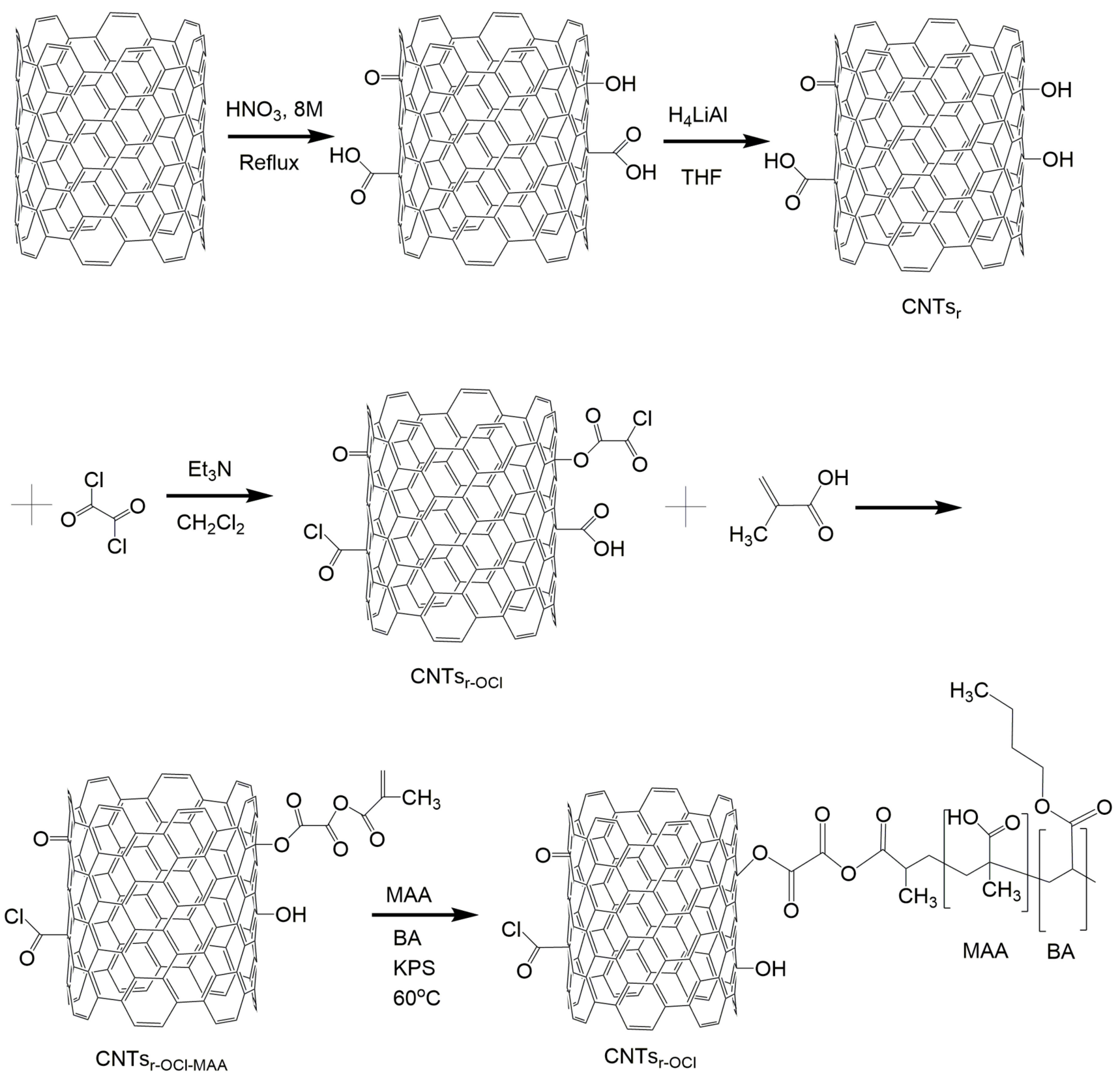

Scheme 1. Chemical route followed to prepare poly(methacrylic acid-co-butyl acrylate) carbon nanotubes $\left(\mathrm{CNTs}_{\mathrm{r}-\mathrm{OCl}-\mathrm{MAA}}{ }^{-}\right.$ BA) nanocomposites.

A brief description of the aforementioned chemical route is described next. Step 1: Three grams of the CNTs $p$ was placed into a $250 \mathrm{~cm}^{3}$ glass Soxhlet apparatus. Then, $150 \mathrm{~cm}^{3}$ of $8 \mathrm{M}$ nitric acid solution was added. The dispersion was kept under reflux for $4 \mathrm{~h}$. The obtained $\mathrm{CNTs}_{\mathrm{o}}$ were purified by separating them from the liquid phase by centrifugation, washed several times with distilled water, and dried at room temperature until constant weight. Step 2: Due to the fact that $\mathrm{OxCl}$ preferentially reacts with hydroxyl groups, a certain amount of the $\mathrm{CNTs}_{\mathrm{o}}$ carboxyl groups was reduced to hydroxyl groups. For this, $25 \mathrm{~cm}^{3}$ of anhydrous THF, $0.50 \mathrm{~g}$ of lithium aluminum hydride, and $0.7 \mathrm{~g}$ of CNTs were placed in a perfectly dry $50 \mathrm{~cm}^{3}$ flask. The reaction was carried out during $3 \mathrm{~h}$ at room temperature, under vigorous stirring. Next, $50 \mathrm{~cm}^{3}$ of methanol was slowly added. Then, $10 \mathrm{~cm}^{3}$ of a $0.1 \% \mathrm{HCl}$ aqueous solution was added. Later, $10 \mathrm{~cm}^{3}$ of a $1 \% \mathrm{HCl}$ aqueous solution was also added to achieve a complete neutralization of the original dispersion. The mixture was filtered out and the obtained $\mathrm{CNTs}_{\mathrm{r}}$ were purified by repeated washing with 
distilled water and dried at room temperature until achieving constant weight. Step 3: A functionalization reaction between $\mathrm{CNTs}_{\mathrm{O}}$ and $\mathrm{CNTs}_{\mathrm{r}}$ with $\mathrm{OxCl}$ was carried out separately. For this, $0.1 \mathrm{~g}$ of $\mathrm{CNTs}_{\mathrm{o}}$ or $0.1 \mathrm{~g}$ of $\mathrm{CNTs}_{\mathrm{r}}$ was placed separately in a $200 \mathrm{~cm}^{3}$ flask, immersed in a water bath at $313.15 \mathrm{~K}$. A mixture of $90 \mu \mathrm{dm}^{3}$ of $\mathrm{Et}_{3} \mathrm{~N}$ and $5 \mathrm{~cm}^{3}$ of dichloromethane was added with a syringe. The mixture was kept under agitation for $15 \mathrm{~min}$. After this, a mixture of $60 \mu \mathrm{dm}^{3}$ of $\mathrm{OxCl}$ and $5 \mathrm{~cm}^{3}$ of dichloromethane was added with a syringe, drop by drop. The reaction was carried out under agitation and $\mathrm{N}_{2}$ bubbling for $3 \mathrm{~h}$. The product $\left(\mathrm{CNTs}_{\mathrm{O}-\mathrm{OCl}}\right.$ or $\left.\mathrm{CNTs}_{\mathrm{r}-\mathrm{OCl}}\right)$ was used immediately after having been obtained. In order to analyze the obtained $\mathrm{CNTs}_{\mathrm{o}-\mathrm{OCl}}$ or $\mathrm{CNTs}_{\mathrm{r}-\mathrm{OCl}}$, a small amount was withdrawn from the flask and dried completely in a vacuum oven at $298.15 \mathrm{~K}$ for $24 \mathrm{~h}$, to eliminate the residual mixture of $\mathrm{OxCl}$ and dichloromethane. Step 4: In the same flask where $\mathrm{CNTs}_{\mathrm{o}-\mathrm{OCl}}$ or $\mathrm{CNTs}_{\mathrm{r}-\mathrm{OCl}}$ was prepared, the necessary amount of MAA to produce the nanocomposites was added. The mixture was kept at room temperature under stirring for $30 \mathrm{~min}$. Two types of products were obtained separately and named $\mathrm{CNTs}_{\mathrm{o}-\mathrm{OCl}-\mathrm{MAA}}$ and $\mathrm{CNTs}_{\mathrm{r}-\mathrm{OCl}-\mathrm{MAA}}$. Each type of product, as prepared, was used immediately to synthesize the nanocomposites, independently. To analyze the obtained $\mathrm{CNTs}_{\mathrm{o}-\mathrm{OCl}-\mathrm{MAA}}$ and $\mathrm{CNTs}_{\mathrm{r}-\mathrm{OCl}-\mathrm{MAA}}$, a sample of these products was withdrawn from the flask and heated for $1 \mathrm{~h}$ at $353.15 \mathrm{~K}$ to eliminate the excess of the MAA by evaporation.

The content of hydroxyl groups created onto $\mathrm{CNTs}_{\mathrm{o}}$ and $\mathrm{CNTs}_{\mathrm{r}}$ surface was determined by the indirect back titration method, based on the total acid groups titratable with $\mathrm{NaOH}$. For this, an excess of $\mathrm{OxCl}$ was reacted with the $\mathrm{CNTs}_{\mathrm{o}}$ and $\mathrm{CNTs}_{\mathrm{r}}$ surface hydroxyl groups. Then, $0.1 \mathrm{~g}$ of $\mathrm{CNTs}_{\mathrm{o}-\mathrm{OCl}}$ or $\mathrm{CNTs}_{\mathrm{r}-\mathrm{OCl}}$ was mixed with $30 \mathrm{~cm}^{3}$ of $\mathrm{NaOH} 0.1 \mathrm{~N}$. The mixture was reacted for $1 \mathrm{~h}$. After this, the excess $\mathrm{NaOH}$ was determined by titration with a $0.1 \mathrm{~N} \mathrm{HCl}$ solution.

The content of carboxyl groups grafted onto $\mathrm{CNTs}_{\mathrm{o}}$ and onto $\mathrm{CNTs}_{\mathrm{r}}$ surface was also determined by the indirect back titration method, using a weaker base (sodium bicarbonate). The method was previously reported [32]. Briefly, a specific amount of CNTs ${ }_{\mathrm{o}}$ and $\mathrm{CNTs}_{\mathrm{r}}$ was reacted with an excess of sodium bicarbonate. Carboxylic acid groups should react forming $\mathrm{CNTs}_{\mathrm{O}}-\mathrm{COO}^{-} \mathrm{Na}^{+}$and $\mathrm{CNTs}_{\mathrm{r}}-\mathrm{COO}^{-} \mathrm{Na}^{+}$. The sodium bicarbonate excess was titrated with an $\mathrm{HCl}(0.1 \mathrm{~N})$ solution.

\subsection{Synthesis and Purification of CNTs $s_{0-O C l-M A A}-B A$ and $C N T s_{r-O C l-M A A}-B A$ Nanocomposites and Their Pure Polymeric Matrix: $M A A-B A$ Copolymer}

The $\mathrm{CNTs}_{\mathrm{o}-\mathrm{OCl}-\mathrm{MAA}}-\mathrm{BA}$ and $\mathrm{CNTs}_{\mathrm{r}-\mathrm{OCl}-\mathrm{MAA}}-\mathrm{BA}$ nanocomposites were prepared by IEP. For this, immediately after $\mathrm{CNTs}_{\mathrm{o}-\mathrm{OCl}-\mathrm{MAA}}$ and $\mathrm{CNTs}_{\mathrm{r}-\mathrm{OCl}-\mathrm{MAA}}$ were prepared, the reagents necessary to prepare the nanocomposites were added in the same flask previously used. Specifically, a solution of $0.5 \mathrm{~g}$ of sodium dodecyl sulfate (SDS), dissolved in $95 \mathrm{~g}$ of water, was used. The mixture was stirred by immersion in an ultrasonic bath for $5 \mathrm{~min}$. The flask was submerged in a water bath at $333.15 \mathrm{~K}$ and $\mathrm{N}_{2}$ gas was bubbled. After $30 \mathrm{~min}$, the necessary amount of BA and a $0.1 \mathrm{~g}$ of KPS solution in $5 \mathrm{~g}$ of water were added. At this point, the reaction was started.

In order to perform an adequate comparison, MAA-BA copolymers were also synthesized. For this, a similar route to the one described to prepare the $\mathrm{CNTs}_{\mathrm{O}-\mathrm{OCl}-\mathrm{MAA}}-\mathrm{BA}$ and CNTs r-OCl-MAA-BA nanocomposites was followed. Now, in a $200 \mathrm{~cm}^{3}$ glass flask, a solution of $0.5 \mathrm{~g}$ of SDS and $95 \mathrm{~g}$ of water was added. The flask was submerged in a water bath at $333.15 \mathrm{~K}$ and $\mathrm{N}_{2}$ gas was bubbled. After $30 \mathrm{~min}$, the necessary mass of MAA, BA, and a solution of $0.1 \mathrm{~g}$ of KPS in $5 \mathrm{~g}$ of water was added, initiating the reaction.

Table 1 lists the contents of MAA and BA used to prepare the MAA-BA copolymers, as well as of these co-monomers and $\mathrm{CNTs}_{\mathrm{O}}$ or $\mathrm{CNTs}_{\mathrm{r}}$ to prepare $\mathrm{CNTs}_{\mathrm{O}-\mathrm{OCl}-\mathrm{MAA}}-\mathrm{BA}$ or $\mathrm{CNTs}_{\mathrm{r}-\mathrm{OCl}-\mathrm{MAA}}-\mathrm{BA}$ nanocomposites. 
Table 1. Content of MAA, BA, $\mathrm{CNTs}_{\mathrm{o}}$, or $\mathrm{CNTs}_{\mathrm{r}}$ used for the preparation of pure MAA-BA copolymers, as well as the $\mathrm{CNTs}_{\mathrm{O}-\mathrm{OCl}-\mathrm{MAA}}-\mathrm{BA}$ or $\mathrm{CNTs}_{\mathrm{r}-\mathrm{OCl}-\mathrm{MAA}}-\mathrm{BA}$ nanocomposites.

\begin{tabular}{|c|c|c|c|c|}
\hline Code & $\begin{array}{c}\text { MAA } \\
\text { (wt.\%) }\end{array}$ & $\begin{array}{c}\text { BA } \\
(w t . \%)\end{array}$ & $\begin{array}{c}\mathrm{CNTs}_{\mathrm{o}}{ }^{1} \\
(w \mathrm{t} . \%)\end{array}$ & $\begin{array}{c}\mathrm{CNTs}_{\mathrm{r}}{ }^{2} \\
\text { (wt. } \% \text { ) }\end{array}$ \\
\hline Mat 1 & 20 & 80 & 0 & 0 \\
\hline Mat 2 & 40 & 60 & 0 & 0 \\
\hline Nano 1 & 20 & 80 & 1 & - \\
\hline Nano 2 & 20 & 80 & - & 1 \\
\hline Nano 3 & 20 & 80 & 0.5 & - \\
\hline Nano 4 & 20 & 80 & - & 0.5 \\
\hline Nano 5 & 40 & 60 & 1 & - \\
\hline Nano 6 & 40 & 60 & - & 1 \\
\hline Nano 7 & 40 & 60 & 0.5 & - \\
\hline Nano 8 & 40 & 60 & - & 0.5 \\
\hline
\end{tabular}

Scheme 1 shows the chemical route used to prepare $\mathrm{CNTs}_{\mathrm{r}-\mathrm{OCl}-\mathrm{MAA}}-\mathrm{BA}$ nanocomposites. A similar chemical path was used to prepare $\mathrm{CNTs}_{\mathrm{o}-\mathrm{OCl}-\mathrm{MAA}}-\mathrm{BA}$ nanocomposites, but without the step that produces the reduction of carboxyl groups.

After synthesizing the $\mathrm{CNTs}_{\mathrm{O}-\mathrm{OCl}-\mathrm{MAA}}-\mathrm{BA}$ and $\mathrm{CNTs}_{\mathrm{r}-\mathrm{OCl}-\mathrm{MAA}}-\mathrm{BA}$ nanocomposites and the MAA-BA copolymers, these materials were purified. For this, the obtained latex was frozen to obtain a solid material. To dissolve the solid latex, a volume of acetone equivalent to the volume of latex was added. Then, the mixture was allowed to thaw-out. A precipitate formation was produced. The solid-liquid mixture was filtered, washed, and water-dialyzed at $343.15 \mathrm{~K}$ for $72 \mathrm{~h}$ to eliminate the residual SDS. The $\mathrm{pH}$ of the washing water was close to 7 . Finally, the purified product was dried in an oven at $323.15 \mathrm{~K}$ until achieving a constant weight. The purified samples of the MAA-BA copolymers and of the $\mathrm{CNTs}_{\mathrm{o}-\mathrm{OCl}-\mathrm{MAA}}-\mathrm{BA}$ and $\mathrm{CNTs}_{\mathrm{r}-\mathrm{OCl}-\mathrm{MAA}}-\mathrm{BA}$ nanocomposites were studied by FT-IR, XPS, NMR, DSC, and UV-VIS techniques.

\subsection{Characterization of $M A A-B A$ Copolymers and Their $C N T s_{0-O C l-M A A}-B A$ and CNTs ${ }_{r-O C l-M A A}-B A$ Nanocomposites}

A battery of techniques was used to characterize synthesized and functionalized CNTs, MAA-BA copolymers, and their nanocomposites. There is special interest in verifying whether the functionalized CNTs were bonded chemically to the polymeric macromolecules of nanocomposites studied.

CNTs were examined with a field emission scanning electron microscope (FE-SEM), model MIRA 3LU of Tescan (Brno, Czech Republic). Samples were prepared by mixing ca. $0.02 \mathrm{~g}$ of CNTs with $2 \mathrm{~cm}^{3}$ of acetone, at room temperature. An aliquot of this dispersion was taken with a Pasteur pipette and poured onto a $\mathrm{Cu}$ grid. After solvent evaporation, the samples were analyzed in the FE-SEM microscope.

CNTs were also examined with a high-resolution JEOL (Tokyo, Japan) transmission electron microscope (model 2010 HRTEM operated at $200 \mathrm{kV}$ ). Here, the samples were prepared by mixing ca. $0.007 \mathrm{~g}$ of CNTs with $2 \mathrm{~cm}^{3}$ of acetone, at room temperature. The obtained mixture was sonicated for $5 \mathrm{~min}$. After this, an aliquot of this dispersion was poured onto a $\mathrm{Cu}$ grid, using a Pasteur pipette. With a $60 \mathrm{~W}$ solar lamp, the solvent was evaporated for $15 \mathrm{~min}$. After this, the sample was placed into the HR-TEM microscope for analysis.

Raman spectroscopy was used to analyze samples of functionalized CNTs. For this, a Dilor (Villeneuve-d'Ascq, France) spectrometer model Lab Raman II was used. This device is equipped with a HeNe laser, which was operated at $20 \mathrm{~mW}$ and at an excitation 
wavelength of $632.8 \mathrm{~nm}$. The measurements were made using a $50 \times$ objective with an area spot of $2 \mathrm{~mm}$ and $2 \mathrm{~cm}^{-1}$ errors.

Structural characterization of $\mathrm{CNTs}_{\mathrm{p}}, \mathrm{CNTs}_{\mathrm{f}}, \mathrm{CNTs}_{\mathrm{O}-\mathrm{OCl}-\mathrm{MAA}}-\mathrm{BA}$ and $\mathrm{CNTs}_{\mathrm{r}-\mathrm{OCl}-\mathrm{MAA}}-$ BA nanocomposites, and MAA-BA copolymers was performed by Fourier-transform infrared spectroscopy (FT-IR spectrophotometer, Spectrum One of Perkin Elmer, Waltham, Massachusetts, USA). For this, pellets formed with $\mathrm{KBr}$ and dry samples were prepared (at a ratio of $1 \mathrm{mg}$ of the sample to $300 \mathrm{mg}$ of $\mathrm{KBr}$ ) by compression at room temperature. Reported spectra were obtained and analyzed from an average of 64 scans, to reduce the signal/noise ratio, and a resolution of $4 \mathrm{~cm}^{-1}$.

Nanocomposites of $\mathrm{CNTs}_{\mathrm{O}-\mathrm{OCl}-\mathrm{MAA}}-\mathrm{BA}$ and $\mathrm{CNTs}_{\mathrm{r}-\mathrm{OCl}-\mathrm{MAA}}-\mathrm{BA}$ and their pure copolymer matrix were analyzed by the X-ray photoelectron spectroscopy (XPS) technique. XPS was carried out using an XR50 M monochromatic Al K $\alpha_{1}(h v=1486.7 \mathrm{eV})$ X-ray source and a Phoibos 150 spectrometer. This equipment has a one-dimensional detector 1D-DLD, provided by SPECS (Berlin, Germany). A set of experiments was mounted on a steel sample holder using double-sided copper tape. Prior to the measurements, the samples were dried in a vacuum oven, at a temperature of $333.15 \mathrm{~K}$ for $48 \mathrm{~h}$. After this, they were introduced into the pre-chamber. All measurements were recorded at $150 \mathrm{~W}$ and takeoff angle of $90^{\circ}$, setting the pass energy at $10 \mathrm{eV}$ and a step size of $0.1 \mathrm{eV}$. The flood gun device was used for charge neutralization on samples. Moreover, spectra were shifted, using the $\mathrm{C}-\mathrm{C}$ position on binding energy.

Solution ${ }^{1} \mathrm{H}$ spectra in DMSO- $\mathrm{d}_{6}$ of the pure MAA-BA copolymers were recorded at room temperature on a Bruker (Billerica, Massachusetts, USA) Avance 500 spectrometer using tetramethylsilane (TMS) as an internal standard.

Solid-state ${ }^{13} \mathrm{C}$ NMR spectra, of the nanocomposites, and of their pure copolymer matrices, were recorded under proton decoupling on a Bruker (Billerica, Massachusetts, USA) Avance 400, operating at $100.613 \mathrm{MHz}$ for ${ }^{13} \mathrm{C}$. A Bruker probe equipped with $4 \mathrm{~mm}$ rotors was used. CP-MAS spectra were obtained under Hartmann-Hahn matching conditions and a spinning rate of $6.0 \mathrm{kHz}$ was used. A contact time of $2.5 \mathrm{~ms}$ and a repetition time of $4 \mathrm{~s}$ were used. The measurements were made using spin-lock power in radiofrequency units of $60 \mathrm{kHz}$ and 4000 transients were typically recorded. Chemical shifts were externally referenced to tetramethylsilane (TMS), using adamantane.

DSC thermograms of the prepared nanocomposites and of their pure polymer matrices were obtained on a TA-Instruments (New Castle, Delaware, USA) calorimeter model Q-100. DSC thermograms were recorded following a heating program from 183.15 to $453.15 \mathrm{~K}$ at a heating rate of $10 \mathrm{~K} / \mathrm{min}$, using a flow rate of $50 \mathrm{~cm}^{3} / \mathrm{min}$ of nitrogen to maintain an inert atmosphere. Two scans were carried out and the second scan is reported.

A study of hydrocortisone release was carried out in vitro by UV-VIS spectroscopy. For this, tablets containing hydrocortisone were prepared previously. To prepare the tablets, samples of the nanocomposites or of their pure polymer matrix were mixed with $1 \%(w / w)$ of hydrocortisone at room temperature. Then, they were placed in a $7 \mathrm{~mm}$ diameter mold and pressed to obtain tablets with $1.5 \mathrm{~mm}$ of thickness. Tablets' final weights were in the range of 35 to $55 \mathrm{mg}$. After tablets preparation, they were placed in $3 \mathrm{~cm}^{3}$ of potassium biphthalate buffer at $\mathrm{pH} 5$ in a quartz cell. The hydrocortisone concentration was determined by the variation of absorbance as a function of time on a Perkin-Elmer (Waltham, Massachusetts, USA) UV-VIS spectrometer Lambda 25, at $248 \mathrm{~nm}$. In addition, the swelling degree of the nanocomposites, and of their polymeric matrix, was measured at room temperature. This was carried out by preparing tablets of pure nanocomposites or MAA-BA copolymers with the same size and weights as those already described above. All tablets were dried until observing constant weight. Then, they were place in a vial with $10 \mathrm{~cm}^{3}$ of potassium biphthalate buffer at $\mathrm{pH} 5$ for $24 \mathrm{~h}$. After this, at certain times, the swollen tablets were then taken out of the vial, wiped with a filter paper, and weighed. The swelling degree $\left(S_{w}\right)$ was calculated with the following equation:

$$
S_{w}=\frac{W_{w}-W_{d}}{W_{d}}
$$


where $W_{d}$ is the weight of dried tablet and $W_{w}$ is the weight of the swollen tablet.

\section{Results and Discussion}

Figure 1A depicts a $\mathrm{CNTs}_{\mathrm{p}}$ micrograph, obtained by FE-SEM. It is evident that the population of $\mathrm{CNTs}_{\mathrm{p}}$ is formed mainly by helical carbon nanotubes (HCNTs). The length of some of them exceeds $2 \mu \mathrm{m}$. Due to the microscope resolution capability, superficial imperfections cannot be detected. The HCNTs' coil-shaped geometry favors their mechanical entanglement with a polymeric matrix. However, to assure a homogeneous dispersion of these nanostructures, it is highly recommended that their surface be previously functionalized. Due to the helical configuration of HCNTs, in which pentagonal/heptagonal carbon rings are periodically repeated, forming superficial defects, the chemical HCNTs' functionalization differs from that used for neat CNTs [33]. Therefore, HCNTs' functionalization requires suitable chemical conditions [34]. In this sense, the chemical modification method to be used can take advantage of the high surface energy state of the HCNTs, induced by their tensile strength, caused by their helical structure [35].
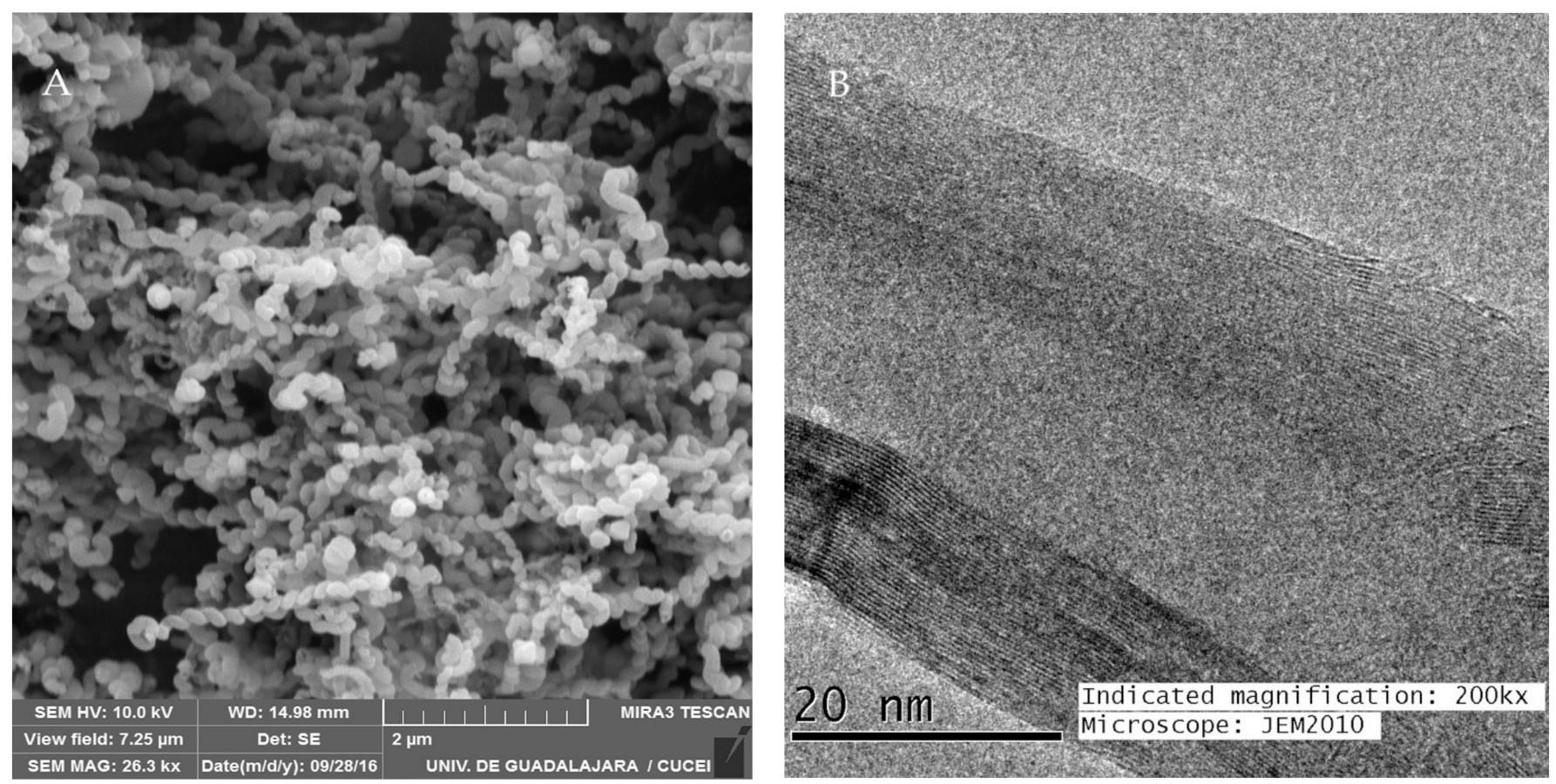

Figure 1. Micrograph of the CNTs $\mathrm{p}_{\mathrm{p}}$ obtained by FE-SEM (A) and micrograph of the CNTs $\mathrm{p}_{\mathrm{p}}$ obtained by HR-TEM (B).

Figure 1B shows an HR-TEM micrograph of the CNTs , including a $20 \mathrm{~nm}$ bar scale, where multiple walls for the structure of CNTs $\mathrm{p}$ can be observed. Based on this micrograph, it is evident that the synthesized and purified CNTs here are helical multiwalled carbon nanotubes (HMWCNTs). In addition, it can be observed that 39 carbon sheets form the walls of the CNTsp sample analyzed. Their inner diameter is $13.8 \mathrm{~nm}$, while the outer diameter is $41.6 \mathrm{~nm}$. The synthesis of HMWCNTs following a catalytic chemical vapor deposition method with Fe nanoparticles as catalysts was reported previously. Nonetheless, in this work, we use a different experimental approach to achieve the HMWCNTs' synthesis, regarding a previously reported approach [36]. HMWCNTs have interesting properties; for example, they can act as an efficient material for the dispersive solid-phase extraction of low and high molecular weight polycyclic aromatic hydrocarbons, from aqueous solutions [37]. In this work, we report the use of synthesized HMWCNTs to prepare $\mathrm{CNTs}_{\mathrm{o}-\mathrm{OCl}-\mathrm{MAA}}-\mathrm{BA}$ and $\mathrm{CNTs}_{\mathrm{r}-\mathrm{OCl}-\mathrm{MAA}}-\mathrm{BA}$ PNs nanocomposites.

The functionalization of prepared CNTs was assessed by various techniques. Initially, the presence of hydroxyl and carboxyl groups on CNTs' walls was evaluated. The amount of hydroxyl and carboxyl groups was quantified following the procedure previously 
described in the Experimental section. It was found that the amount of hydroxyl groups was $2.3 \mathrm{mmol}$ per gram in $\mathrm{CNTs}_{\mathrm{o}}$ and $7.6 \mathrm{mmol}$ per gram in $\mathrm{CNTs}_{\mathrm{r}}$, while the amount of carboxyl groups was $2.8 \mathrm{mmol}$ per gram of $\mathrm{CNTs}_{\mathrm{o}}$ and $1.3 \mathrm{mmol}$ per gram in $\mathrm{CNTs}_{\mathrm{r}}$. These results confirm that the transformation of carboxyl groups attached to $\mathrm{CNTs}_{\mathrm{o}}$ walls to hydroxyl groups inserted on $\mathrm{CNTs}_{\mathrm{r}}$ walls was successfully achieved.

Figure 2 shows the functionalized CNTs' Raman spectra. The four Raman spectra show a similar pattern: three peaks are clearly resolved. In the CNTs spectrum, other Raman contributions of minor intensity are detected. Table 2 lists the frequencies of the three mentioned bands. The graphite band (G-band) is detected at ca. $1574 \mathrm{~cm}^{-1}$. This is a first-order Raman band, and is related to the tangential vibration of two carbon atoms, in one graphene unit cell. This cell is the basic structure of graphene sheets that rolled-up to form the CNTs' walls. G-band is associated with the crystallinity degree of graphene sheets. In addition, it is considered to be due to the highly ordered carbon structures, like those that form the nanotube walls. As a shoulder of the G-band, the $\mathrm{G}^{*}$-band, at around $1612 \mathrm{~cm}^{-1}$, was detected. The $\mathrm{G}^{*}$-band is a lesser-known disorder-induced band [38]. The results listed in Table 2 reveal that the G-band of HMWCNTs, functionalized with acyl chloride functionality $\left(\mathrm{CNTs}_{\mathrm{O}-\mathrm{OCl}}\right.$ and $\left.\mathrm{CNTs}_{\mathrm{r}-\mathrm{OCl}}\right)$, shifts at lower frequencies, with respect to their precursors $\left(\mathrm{CNTs}_{\mathrm{o}}\right.$ and $\left.\mathrm{CNTs}_{\mathrm{r}}\right)$. This is because the $\mathrm{CNTs}^{\prime}$ vibrational response is modified by the introduction of guest molecules, with donor or acceptor electronic characteristics $[39,40]$. This behavior confirms that the chemical groups attached to the walls of $\mathrm{CNTs}_{\mathrm{o}-\mathrm{OCl}}$ and $\mathrm{CNTs}_{\mathrm{r}-\mathrm{OCl}}$ have a different chemical structure, as compared to those attached to $\mathrm{CNTs}_{\mathrm{o}}$ and $\mathrm{CNTs}_{\mathrm{r}}$. At lower frequencies, a disorder-induced mode, called D-band (at ca. $1323 \mathrm{~cm}^{-1}$ ), was detected. This band originates from a double-resonance process, in which an elastic scattering and an inelastic scattering caused by a defect and by a phonon, respectively, is developed [41]. In a fashion similar to the one observed for the G-band, the D-band on the samples of the $\mathrm{CNTs}_{\mathrm{o}-\mathrm{OCl}}$ and $\mathrm{CNTs}_{\mathrm{r}-\mathrm{OCl}}$ was detected at a lower frequency, with respect to that of their $\mathrm{CNTs}_{\mathrm{o}}$ and $\mathrm{CNTs}_{\mathrm{r}}$ precursors. Table 2 also lists two ratios, calculated from integrated areas of the $D$ and $G$ bands $\left(I_{D} / I_{G}\right)$ or the $\mathrm{G}^{*}$ and $\mathrm{G}$ bands $\left(\mathrm{I}_{\mathrm{G}^{*}} / \mathrm{I}_{\mathrm{G}}\right)$. These ratios are typically used to evaluate the disorder degree on CNTs' walls. This disorder is related to the amount of functional groups covalently attached to the CNTs' surface. It is evident that both ratios increase for $\mathrm{CNTs}_{\mathrm{o}-\mathrm{OCl}}$ with respect to $\mathrm{CNTs}_{\mathrm{O}}$, but decrease for the $\mathrm{CNTs}_{\mathrm{r}-\mathrm{OCl}}$ compared to $\mathrm{CNTs}_{\mathrm{r}}$. This result indicates that a reordering within the carbon nanotubes $\mathrm{CNTs}_{\mathrm{r}-\mathrm{OCl}}$ has taken place. As the amount of hydroxyl groups in $\mathrm{CNTs}_{\mathrm{r}}$ is larger than that in $\mathrm{CNTs}_{\mathrm{o}}$, it is likely that the hydrogen bonds of carbon nanotubes of $\mathrm{CNTs}_{\mathrm{r}-\mathrm{OCl}}$ increase with respect to the ones present in $\mathrm{CNTs}_{\mathrm{o}-\mathrm{OCl}}$. This factor would influence the creation of a more ordered assembly of carbon nanotubes in $\mathrm{CNTs}_{\mathrm{r}-\mathrm{OCl}}$. At higher frequencies, a D-band overtone called " $\mathrm{G}^{\prime}$-band" was observed. The G'-band is caused by a double-resonance process. The G'-band, for the different types of functionalized CNTs studied in this work, shows a different intensity. This is caused by the different structural arrangements of CNTs.

Table 2. Wavenumbers of the $\mathrm{D}, \mathrm{G}, \mathrm{G}^{*}$, and $\mathrm{G}^{\prime}$ Raman bands, and scattering intensities ratios $\left(\mathrm{I}_{\mathrm{D}} / \mathrm{I}_{\mathrm{G}}\right.$ and $\mathrm{I}_{\mathrm{G}^{*}} \mathrm{I}_{\mathrm{G}}$ ) of $\mathrm{CNTs}_{\mathrm{o}}, \mathrm{CNTs}_{\mathrm{r}}, \mathrm{CNTs}_{\mathrm{o}-\mathrm{OCl}}$, and $\mathrm{CNTs}_{\mathrm{r}-\mathrm{OCl}}$.

\begin{tabular}{|c|c|c|c|c|c|c|}
\hline Sample & $\begin{array}{l}\text { D-Band } \\
\left(\mathrm{cm}^{-1}\right)\end{array}$ & $\begin{array}{l}\text { G-Band } \\
\left(\mathrm{cm}^{-1}\right)\end{array}$ & $\begin{array}{c}\mathrm{G}^{*} \text {-Band } \\
\left(\mathrm{cm}^{-1}\right)\end{array}$ & $\begin{array}{c}\mathrm{G}^{\prime}-\text { Band } \\
\left(\mathrm{cm}^{-1}\right)\end{array}$ & $\mathbf{I}_{\mathbf{D}} / \mathbf{I}_{G}$ & $\mathbf{I}_{\mathrm{G}^{*} / \mathbf{I}_{\mathrm{G}}}$ \\
\hline $\mathrm{CNTs}_{\mathrm{O}}$ & 1326 & 1574 & 1612 & 2653 & 1.16 & 0.176 \\
\hline $\mathrm{CNTs}_{\mathrm{r}}$ & 1323 & 1577 & 1605 & 2645 & 6.08 & 0.354 \\
\hline $\mathrm{CNTs}_{\mathrm{o}-\mathrm{OCl}}$ & 1322 & 1570 & 1608 & 2651 & 5.16 & 0.274 \\
\hline $\mathrm{CNTs}_{\mathrm{r}-\mathrm{OCl}}$ & 1320 & 1564 & 1600 & 2638 & 1.89 & 0.246 \\
\hline
\end{tabular}




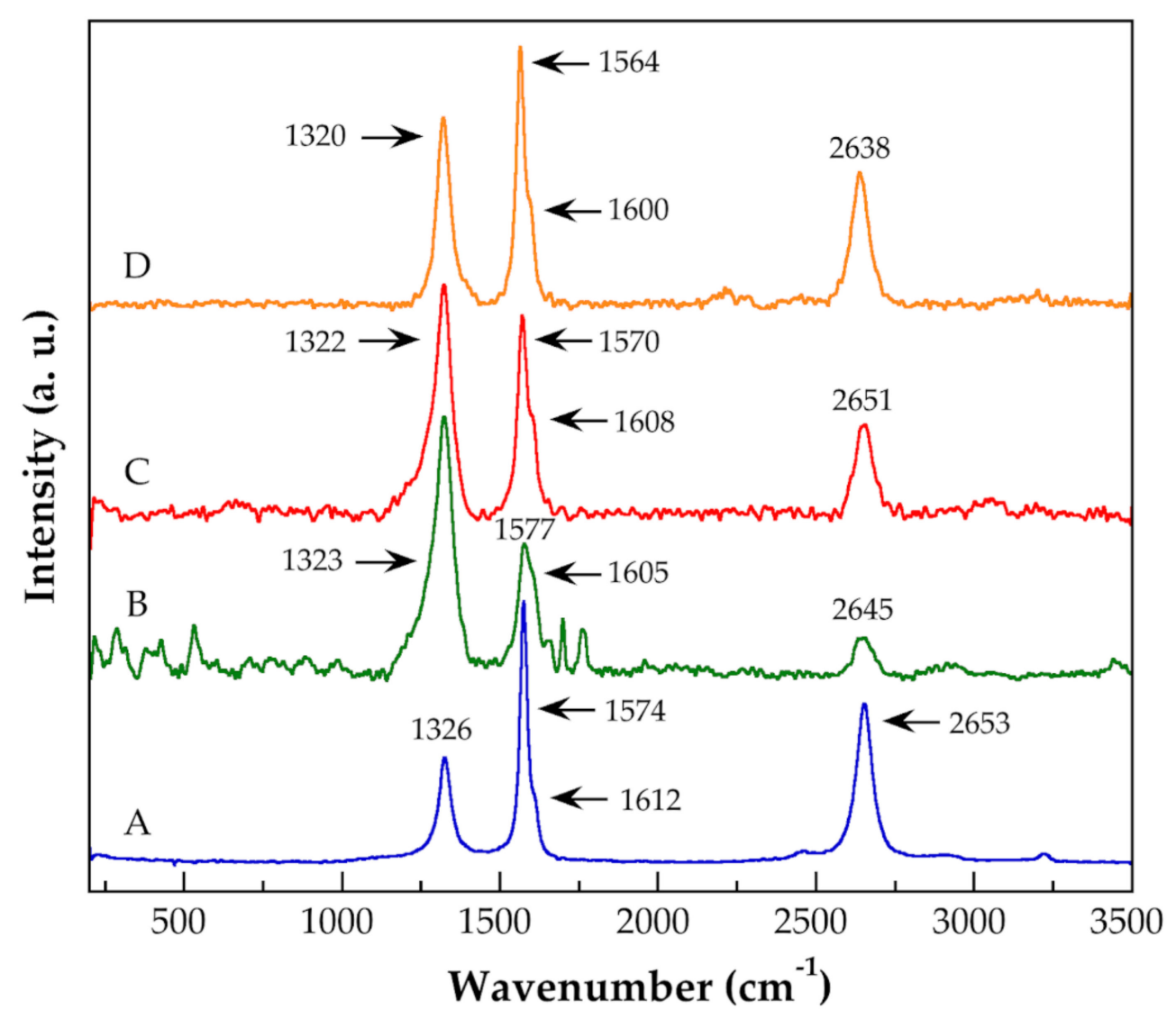

Figure 2. Raman spectra of $\mathrm{CNTs}_{\mathrm{o}}(\mathbf{A}), \mathrm{CNTs}_{\mathrm{r}}(\mathbf{B}), \mathrm{CNTs}_{\mathrm{O}-\mathrm{OCl}}(\mathbf{C})$, and $\mathrm{CNTs}_{\mathrm{r}-\mathrm{OCl}}$ (D).

Figure 3 shows the FT-IR spectra of purified and functionalized CNTs. For comparison, the FT-IR spectrum of pure MAA monomer was included (Figure 3D). The CNTs $\mathrm{C}_{\mathrm{p}}$ FT-IR spectrum (Figure 3A) shows an intense wide band at $3430 \mathrm{~cm}^{-1}$, due to the hydroxyl groups' stretching vibration, and a weak band at $798 \mathrm{~cm}^{-1}$, caused by out-of-plane bending vibration of the $\mathrm{C}-\mathrm{H}$ bond. In the FT-IR spectrum of $\mathrm{CNTs}_{\mathrm{o}}$ (Figure $3 \mathrm{~B}$ ), other spectral contributions appear. At $1020 \mathrm{~cm}^{-1}$, a band due to stretching vibration of the $\mathrm{C}-\mathrm{O}$ bond was detected. The weak and wide band detected at $612 \mathrm{~cm}^{-1}$ is assigned to vibrations of the C$\mathrm{OH}$ torsional band. Moreover, it is evident that the band, due to hydroxyl groups' stretching vibration, becomes wider than the one detected in the $\mathrm{CNTs}_{\mathrm{p}}$ spectrum (Figure $3 \mathrm{~A}$ ). This fact provides evidence that the population of hydroxyl groups increases in the $\mathrm{CNTs}_{\mathrm{o}}$. The FT-IR spectrum of $\mathrm{CNTs}_{\mathrm{o}-\mathrm{OCl}}$ (Figure 3C) shows spectral contributions that indicate acyl chloride groups are attached to the $\mathrm{CNTs}_{\mathrm{o}-\mathrm{OCl}}{ }^{\prime}$ walls. Thus, the stretching vibration of the $\mathrm{C}-\mathrm{Cl}$ bond appears at $807 \mathrm{~cm}^{-1}$, and the harmonic band of this vibration was detected at $1480 \mathrm{~cm}^{-1}$. The last band appears as a shoulder of the band detected at $1475 \mathrm{~cm}^{-1}$. This last peak is assigned to $\mathrm{C}-\mathrm{H}$ bending vibration bonds, created near holes and imperfections in CNTs' walls, due to the functionalization process. At $1764 \mathrm{~cm}^{-1}$, a weak band appears due to the stretching vibration of the carbonyl group that forms part of acyl chloride functionality. At $1037 \mathrm{~cm}^{-1}$, the band with a stronger intensity of this spectrum emerges. This band is assigned to vibration stretching of the $\mathrm{C}-\mathrm{O}$ functionality of an ether group, which includes an aryl group. Due to the fact that CNTs have walls, typically formed by hexagonal carbon rings, they have an aromatic nature like that of the aryl group; therefore, this band confirms that the $\mathrm{C}-\mathrm{O}$ functionality is attached to $\mathrm{CNTs}_{\mathrm{o}-\mathrm{OCl}}$ walls. Furthermore, the hydroxyl groups' band detected at ca. $3500 \mathrm{~cm}^{-1}$ practically disappears (when compared with the observed in Figure $3 \mathrm{~A}, \mathrm{~B}$ ). This fact strongly suggests that the hydroxyl groups of the precursor $\mathrm{CNTs}_{\mathrm{o}}$ have reacted. The FT-IR spectrum of the pure monomer MAA (Figure 3D) shows that their carboxyl groups are grouped forming dimers. This is because at $1701 \mathrm{~cm}^{-1}$, a band appears due to the stretching vibration of carboxyl 
groups self-associated by hydrogen bonding. Besides, the stretching of the $\mathrm{C}=\mathrm{C}$ bond produces the band observed at $1634 \mathrm{~cm}^{-1}$. Regarding the $\mathrm{CNTs}_{\mathrm{O}-\mathrm{OCl}-\mathrm{MAA}} \mathrm{FT}$-IR spectrum (Figure $3 \mathrm{E}$ ), it was analyzed whether a chemical reaction between MAA and $\mathrm{CNTs}_{\mathrm{o}-\mathrm{OCl}}$ was performed. In this spectrum, a weak band at $1848 \mathrm{~cm}^{-1}$ appears. This band is due to the symmetric stretching vibration of the anhydride group. In addition, the antisymmetric stretching vibration of the anhydride group was detected by another weak band, appearing at $1785 \mathrm{~cm}^{-1}$ as a shoulder of the $1740 \mathrm{~cm}^{-1}$ band. The last signal is assigned to the stretching vibration of a carbonyl group of ketone functionality. The detection of IR bands characteristic of vibrations of anhydride groups indicates that a grafting reaction did occur between the superficial acyl chloride groups of $\mathrm{CNTs}_{\mathrm{o}-\mathrm{OCl}}$ and the MAA hydroxyl groups. The stretching vibration of the $\mathrm{C}-\mathrm{O}$ bond of an ether functionality causes the band detected at $1021 \mathrm{~cm}^{-1}$, while the stretching vibrations of $\mathrm{C}-\mathrm{H}$ bonds of methyl groups and hydroxyl groups produce the intense and broad signal, detected at $2991 \mathrm{~cm}^{-1}$ [42]. The last groups are associated via hydrogen bonds with carbonyl groups. The spectral behavior described above confirms that MAA molecules reacted with acyl chloride groups, present in the walls of $\mathrm{CNTs}_{\mathrm{O}-\mathrm{OCl}}$, to form the product that we called $\mathrm{CNTs}_{\mathrm{o}-\mathrm{OCl}-\mathrm{MAA}}$. Similar behavior was observed in the $\mathrm{CNTs}_{\mathrm{r}-\mathrm{OCl}-\mathrm{MAA}}$ FT-IR spectrum.

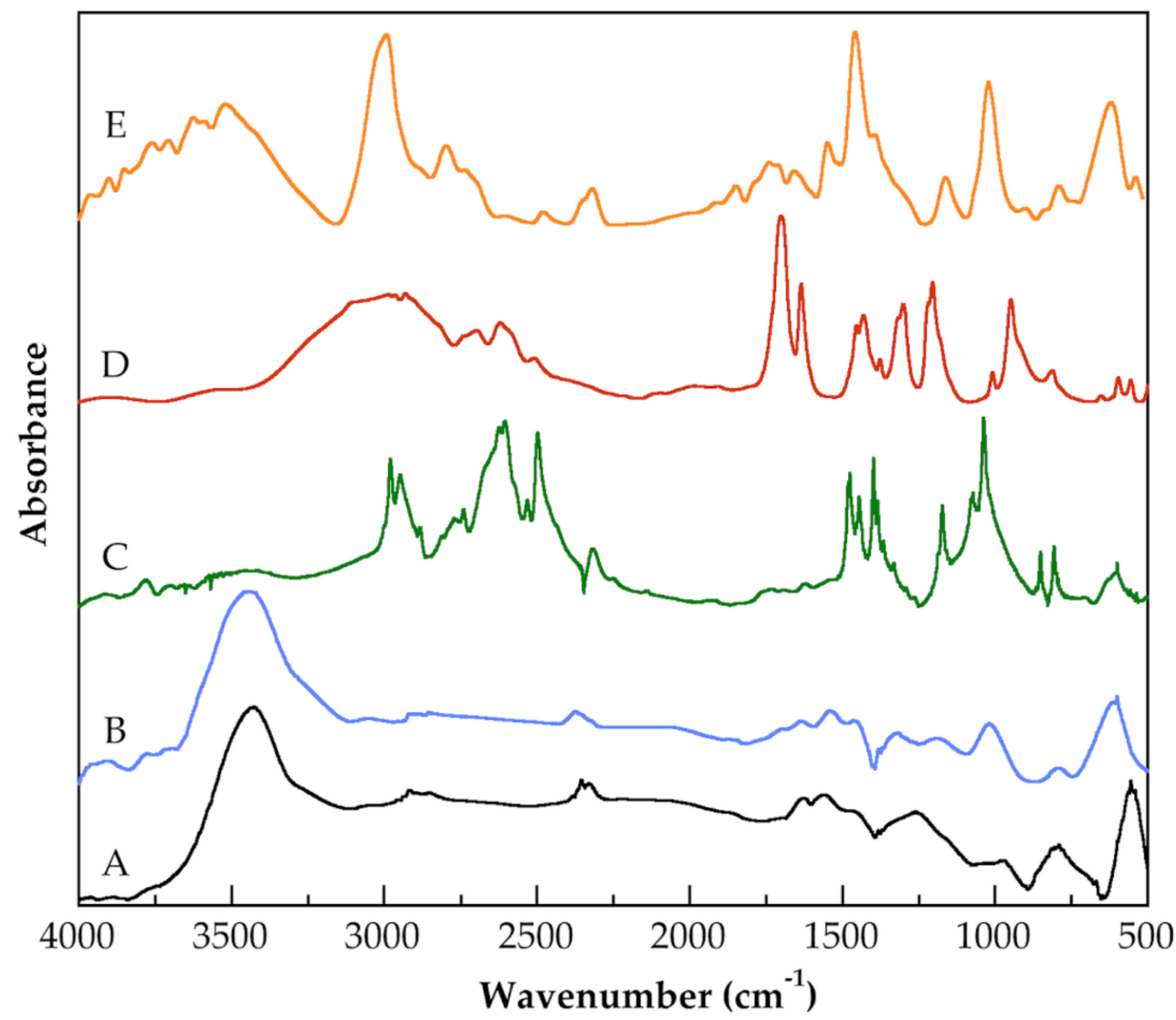

Figure 3. FT-IR spectra of $\mathrm{CNTs}_{\mathrm{p}}(\mathbf{A}), \mathrm{CNTs}_{\mathrm{o}}(\mathbf{B}), \mathrm{CNTs}_{\mathrm{o}-\mathrm{OCl}}(\mathbf{C})$, pure MAA (D), and $\mathrm{CNTS}_{\mathrm{O}-\mathrm{OCl}-\mathrm{MAA}}(\mathrm{E})$.

${ }^{1} \mathrm{H}$ spectra of Mat 1 and Mat 2 were obtained (shown in the Supporting Information). In these spectra, the typical signals of MAA and BA co-monomers were identified. Both co-monomers did react to form the pure polymer matrix of the nanocomposites studied. The spectral contributions observed in these spectra confirm that the MAA-BA copolymer was synthesized successfully following the chemical route reported here. Unfortunately, overlapping of the signals of MAA and BA prevents calculating the composition of MAABA copolymer. 
Figure 4 depicts the ${ }^{13} \mathrm{C}$ NMR CP-MAS spectra of Mat 2 (Figure 4A) and Nano 6 (Figure 4B). The chemical structure of the MAA-BA copolymer has been inserted in Figure $4 \mathrm{~A}$. The following peaks can be observed: at $173.8 \mathrm{ppm}$, a carbonyl group signal $a$; at $65.6 \mathrm{ppm}$, a peak (identified as signal $\mathrm{g}$ ) of the methylene carbon of the $\mathrm{O}=\mathrm{C}-\mathrm{O}-\mathrm{CH}_{2}-$ ester functionality [43]. Further, at $42.8 \mathrm{ppm}$, the signal $f$ of the methylene groups of the BA units and signal $c$ for the MAA moiety can be observed, as well as the signal $e$ at $33.3 \mathrm{ppm}$ corresponding to $-\mathrm{CH}-\mathrm{C}=\mathrm{O}$ functionality. The signal $h$ at $29.4 \mathrm{ppm}$ corresponds to the carbon of methylene groups of the $-\mathrm{CH}_{2}-\mathrm{CH}_{2}$ - functionality. Finally, at $26.0 \mathrm{ppm}$, the signals $j, i$ of the carbon of methylene and methyl groups $\left(-\mathrm{CH}_{2}-\mathrm{CH}_{3}\right.$ functionalities) of BA units were detected. The methyl group, signal $d$, can contribute to the intensity of the signal detected at $26.0 \mathrm{ppm}$. These signals confirm the synthesis of an MAA-BA copolymer.

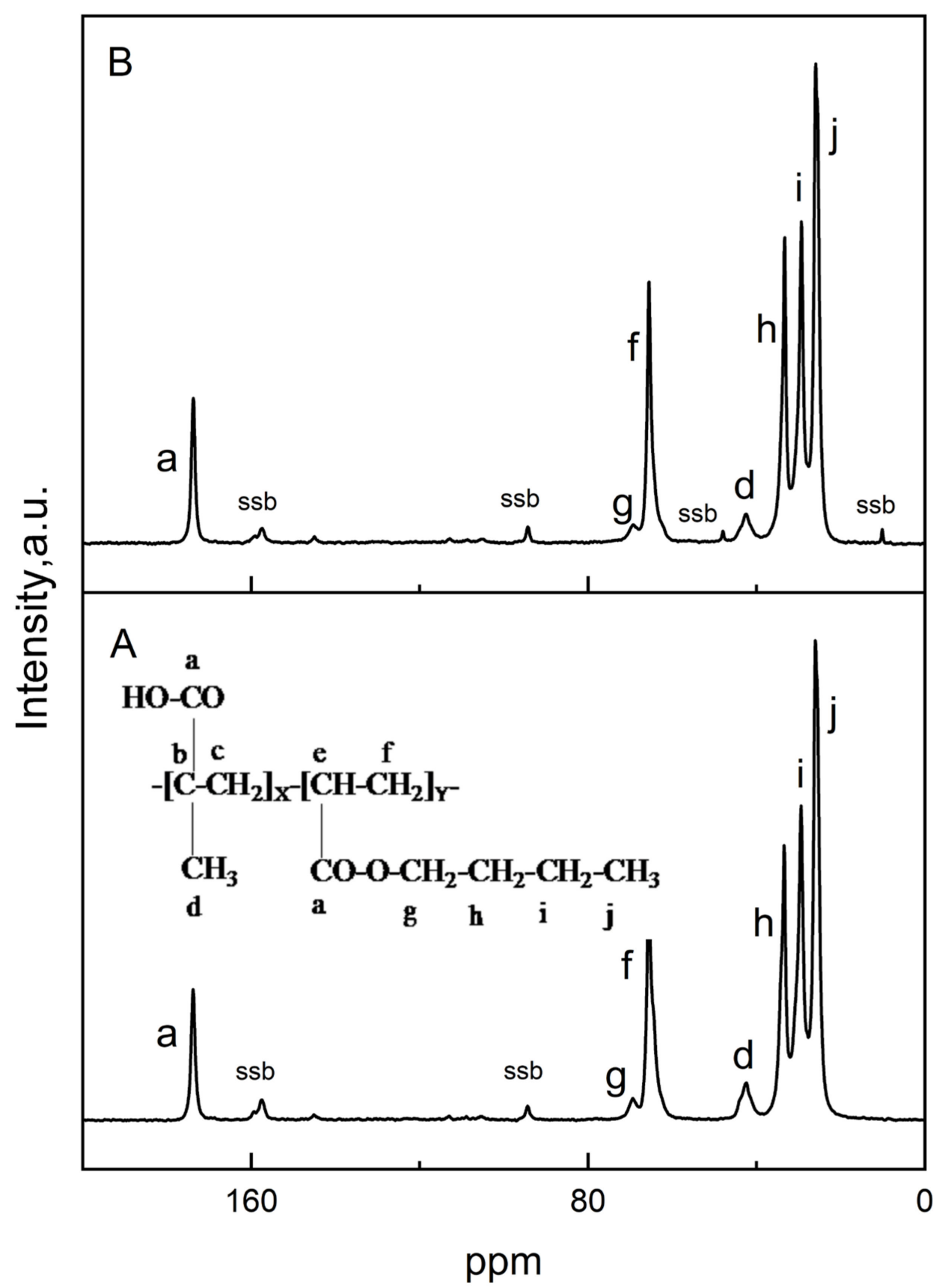

Figure 4. Solid-state ${ }^{13}$ C NMR CP-MAS spectra of Mat 2 (A) and Nano $6(\mathbf{B})$, in which ssb = spinning sidebands. 
The ${ }^{13} \mathrm{C}$ NMR CP-MAS spectra shown in Figure 4 are alike. The only differences emerge in the aliphatic carbons' sidebands that appear at 48 and $10 \mathrm{ppm}$ in the Nano 6 spectrum, which were absent in the Mat 2 spectrum. Both samples were rotated at the same rate. In a CP-MAS experiment, the purpose of rotation about the magic angle is the isotropic average of the chemical shift anisotropy (CSA) shielding tensor to a single peak [44,45]. The appearance of spinning sidebands is because the magic angle spinning (MAS) rate is less than the CSA frequency range. It is expected that the presence of the nanofiller $\left(\mathrm{CNTs}_{\mathrm{r}-\mathrm{OCl}} \mathrm{MAA}_{\mathrm{A}}\right)$ induces a different pattern in the sidebands of the nanocomposite. This is due to the fact that nanofillers induce the formation of ordered domains in their vicinity, not present in the amorphous MMA-BA copolymer. In the ordered domains, chemical shift anisotropy of polymeric backbone cannot be completely eliminated at the spinning rate used.

Figure 5 shows the normalized C1s core level spectra of Mat 2 (Figure 5A), Nano 6 (Figure 5B), and Nano 8 (Figure 5C). To fit the obtained data, we used the active background approach, which is accomplished by the software AAnalyzer 1.42 [46]. All spectra were adjusted to their respective shifts, according to the $\mathrm{C}-\mathrm{C} / \mathrm{C}-\mathrm{H}$ bonds position at $284.8 \mathrm{eV}$. The normalized C1s core level spectrum of Mat 2 (Figure 5A) shows four components: at $284.8 \mathrm{eV}$, a contribution due to $\mathrm{C}-\mathrm{C} / \mathrm{C}-\mathrm{H}$ bonds [47], at $285.5 \mathrm{eV}$ this contribution is assigned to $\underline{\mathrm{C}}-\mathrm{C}=\mathrm{O}$ functionality [48], the contribution observed at $286.4 \mathrm{eV}$ is due to ether $(\mathrm{C}-\mathrm{O})$ bond $[47,48]$, while the contribution that appears at $288.9 \mathrm{eV}$ is due to ester $(\mathrm{O}=\mathrm{C}-\mathrm{O})$ functionality $[47,48]$. The calculated atomic concentrations of these groups are $33.7 \%, 17.7 \%, 9.0 \%$, and $8.2 \%$, respectively. In the normalized C1s core level spectra of the Nano 6 (Figure 5C) and Nano 8 (Figure 5B), the same contributions were found at the same positions. Specifically, for the Nano 6, the components and their atomic concentrations are $284.8 \mathrm{eV}(\mathrm{C}-\mathrm{C} / \mathrm{C}-\mathrm{H}) 36.3 \%, 285.4 \mathrm{eV}(\mathrm{C}-\mathrm{C}=\mathrm{O}) 20.7 \%, 286.4 \mathrm{eV}(\mathrm{C}-\mathrm{O}) 5.1 \%$, and $288.9 \mathrm{eV}$ $(\mathrm{O}=\mathrm{C}-\mathrm{O}) 12.7 \%$. For Nano 8 , the components and their atomic concentrations are $284.8 \mathrm{eV}$ (C-C/C-H) 33.6\%, $285.4 \mathrm{eV}(\mathrm{C}-\mathrm{C}=\mathrm{O}) 22.3 \%, 286.4 \mathrm{eV}(\mathrm{C}-\mathrm{O}) 10.1 \%$, and $288.9 \mathrm{eV}(\mathrm{O}=\mathrm{C}-$ O) $10.3 \%$. For both nanocomposites, the more significant change was that the atomic concentration of functionalities containing carbonyl group increases. In particular, this highlights the changes detected corresponding to the $\mathrm{O}=\mathrm{C}-\mathrm{O}$ functionality contribution. Thus, for Mat 2, the concentration of this functionality was $8.2 \%$, while Nano 6 was $12.7 \%$ and Nano 8 was $10.3 \%$. For the anhydride functionality $\left(\mathrm{R}_{1}-(\mathrm{C}=\mathrm{O})-\mathrm{O}-(\mathrm{C}=\mathrm{O})-\mathrm{R}_{2}\right)$, it has been reported that the signal for the anhydride group is observed at 289.42 or $289.36 \mathrm{eV}$ [48]. The integration for the contribution mentioned was made from 287.83 to $290.23 \mathrm{eV}$. Therefore, the change observed in the XPS spectra of the nanocomposites Nano 6 and Nano 8 indicates that anhydride groups were created as a consequence of the chemical route used for their preparation.

Table 3 lists the areas of two types of signals: (i) carbonyl bond found by ${ }^{13} \mathrm{C}-\mathrm{NMR}$ and (ii) $\mathrm{O}-\mathrm{C}=\mathrm{O}$ functionality detected by XPS. The ratio of the carbonyl group to methyl group areas (the stronger signal of ${ }^{13} \mathrm{C}$ NMR CP-MAS spectra) is reported. In a similar way, the ratio of the signals of $\mathrm{O}-\mathrm{C}=\mathrm{O}$ functionality to $\mathrm{C}-\mathrm{H}$ bonds (the stronger signal of XPS spectra) was also recorded. Consequently, both ratios are normalized signals. It is evident that there is a close similarity in these ratios. Although the levels of analysis for XPS (over the surface) and NMR (the complete mass of the sample) techniques are different, these results show that more carbonyl groups were created in the nanocomposites, with respect to those detected on pure MAA-BA copolymers. Therefore, because $\mathrm{O}-\mathrm{C}=\mathrm{O}$ functionality is part of the anhydride groups, it is evident that these results support the previous FTIR analysis. The anhydride groups are the result of the reaction between acyl chloride groups, attached to CNTs' wall, and hydroxyl groups of MAA monomer. The chemical reaction between acyl chloride groups and hydroxyl groups, to form anhydride groups, has been previously documented for other systems [49]. The formation of MAA-BA chains was carried out from CNTs' walls, where hydroxyl groups of MAA reacted with acyl chloride groups attached to $\mathrm{CNTs}_{\mathrm{o}-\mathrm{OCl}}{ }^{\prime}$ walls or to $\mathrm{CNTs}_{\mathrm{r}-\mathrm{OCl}}{ }^{\prime}$ walls, forming anhydride groups in $\mathrm{CNTs}_{\mathrm{O}-\mathrm{OCl}-\mathrm{MAA}}$ or in $\mathrm{CNTs}_{\mathrm{r}-\mathrm{OCl}-\mathrm{MAA}}$, and allowing a $\mathrm{C}=\mathrm{C}$ bond being available 
to polymerize by radical polymerization under IEP process. Therefore, it can be stated that MAA-BA chains were grafted onto the surface of the functionalized CNTs. It is expected that the grafting efficiency of this reaction is not total.

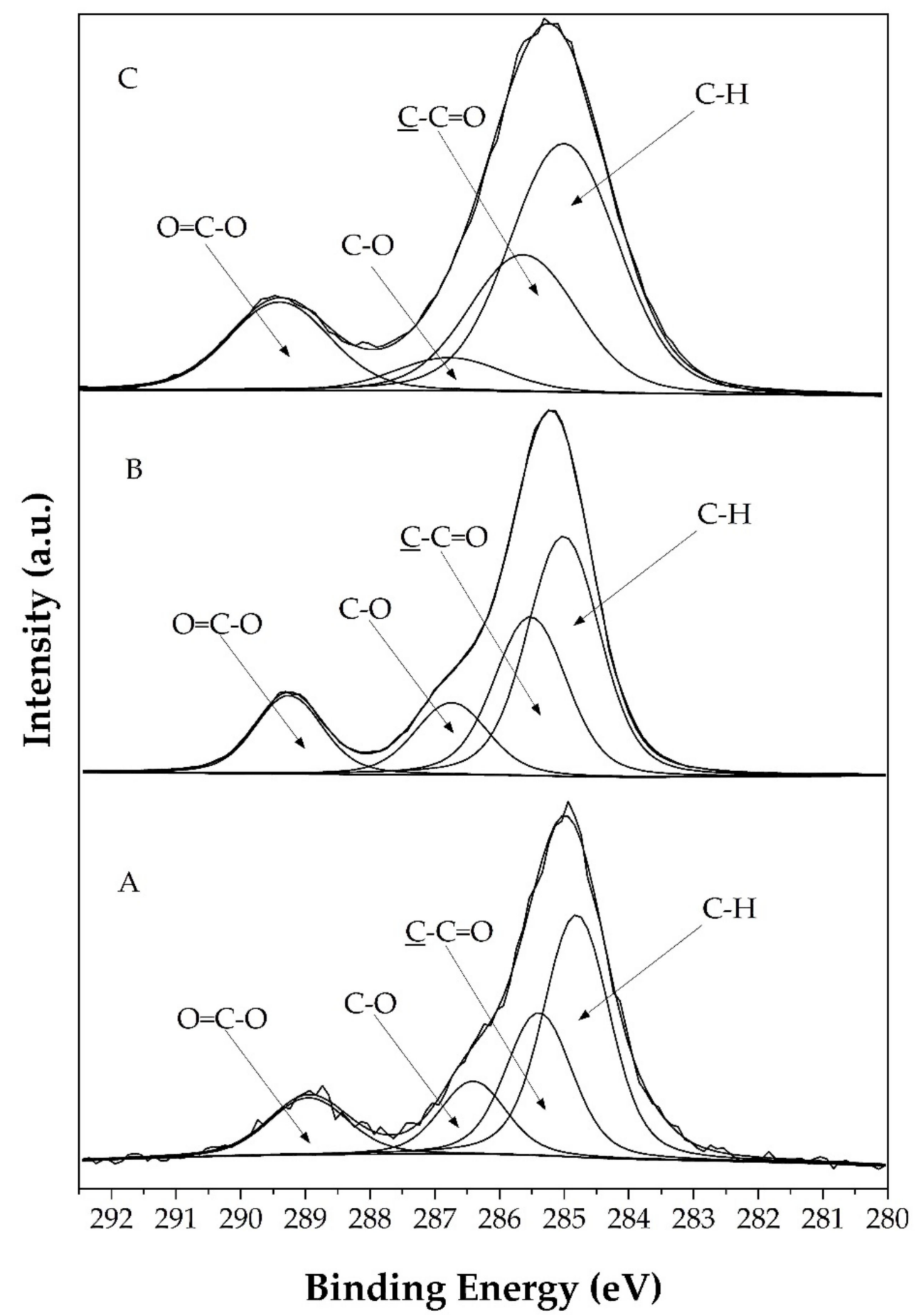

Figure 5. The C1s core level spectra of Mat 2 (A), Nano 8 (B), and Nano 6 (C). 
Table 3. Comparison of copolymer and nanocomposites materials' areas obtained by ${ }^{13} \mathrm{C}-\mathrm{NMR}$ and XPS techniques.

\begin{tabular}{|c|c|c|c|c|}
\hline Code & $\begin{array}{c}\text { Area of } \mathrm{C}=\mathrm{O} \text { Signal } \\
\text { Detected by } \\
{ }^{13} \mathrm{C} \text { NMR }\end{array}$ & $\begin{array}{c}\text { Area of } \\
\text { O-C=O Signal } \\
\text { Observed by XPS }\end{array}$ & $\begin{array}{c}\text { Ratio of } \mathrm{C}=\mathrm{O} / \mathrm{CH}_{3} \\
\text { Signals Measured by } \\
{ }^{13} \mathrm{C} \text { NMR }\end{array}$ & $\begin{array}{c}\text { Ratio of } \\
\text { O-C=O/C-H Signals } \\
\text { Evaluated by XPS }\end{array}$ \\
\hline Mat 1 & 0.06 & 128.8 & 0.19 & 0.20 \\
\hline Mat 2 & 0.06 & 93.8 & 0.20 & 0.17 \\
\hline Nano 1 & 0.07 & 182.8 & 0.21 & 0.20 \\
\hline Nano 2 & 0.07 & 989.9 & 0.23 & 0.18 \\
\hline Nano 3 & 0.07 & 146.4 & 0.21 & 0.20 \\
\hline Nano 4 & 0.07 & 972.9 & 0.23 & 0.23 \\
\hline Nano 5 & 0.07 & 1661.4 & 0.21 & 0.21 \\
\hline Nano 6 & 0.07 & 150.2 & 0.23 & 0.22 \\
\hline Nano 7 & 0.07 & 2119 & 0.21 & 0.20 \\
\hline Nano 8 & 0.07 & 143.2 & 0.23 & 0.17 \\
\hline
\end{tabular}

Figure 6 shows DSC thermograms of the pure MAA-BA copolymer matrix and the ones of the nanocomposites prepared with $0.5 \mathrm{wt} . \%$ of $\mathrm{CNTs}_{\mathrm{o}}$ or $\mathrm{CNTs}_{\mathrm{r}}$. Table 4 shows the thermal transition detected on the corresponding thermograms. This thermal transition is a glass transition temperature. Both poly(methacrylic acid) (PMAA) and poly(butyl acrylate) (PBA) are amorphous polymers. The reported glass transition temperature $\left(T_{\mathrm{g}}\right)$ of PMAA is $501.15 \mathrm{~K}$ [50], while the $T_{\mathrm{g}}$ of PBA is $221.15 \mathrm{~K}$ [51]. The Mat 1 and Mat $2 \mathrm{DSC}$ thermograms show only one $T_{\mathrm{g}}$ in each case. The $T_{\mathrm{g}}$ of Mat 1 is $6279.15 \mathrm{~K}$, while the $T_{\mathrm{g}}$ of Mat 2 is $304.15 \mathrm{~K}$. As expected, as more MAA monomer is used to prepare the MAA-BA copolymer, the $T_{\mathrm{g}}$ of MAA-BA copolymer is detected at higher temperatures. The fact that the amorphous phase of Mat 1 and Mat 2 has only one thermal relaxation (one $T_{\mathrm{g}}$ ) indicates that both copolymers have a random structure, which is the typical structure of copolymers, prepared following a free-radical polymerization. For the nanocomposites, one or two thermal transitions were detected: (i) in the DSC thermograms of Nano 1, Nano 5, Nano 6, and Nano 8, only one $T_{\mathrm{g}}$ was detected, while (ii) the DSC thermograms of Nano 2, Nano 3, Nano 4, and Nano 7 nanocomposites show two $T_{\mathrm{g}} \mathrm{s}$. Since in general, for nanocomposites prepared with a high amount of BA and a low amount of $\mathrm{CNTs}_{\mathrm{O}-\mathrm{OCl}}$ or $\mathrm{CNTs}_{\mathrm{r}-\mathrm{OCl}}$, two glass transition temperatures are observed, we consider that both factors facilitate the segregation of BA and MAA domains, which, in turn, is confirmed by the two observed $T_{\mathrm{g}} \mathrm{s}$. In this respect, a low amount of $\mathrm{CNTs}_{\mathrm{o}}$ or $\mathrm{CNTs}_{\mathrm{r}}$ favors the homogeneous dispersion of both types of $\mathrm{CNTs}_{\mathrm{f}}$. In addition, a higher amount of BA favors that, even though the polymerization process is carried out by free radicals, domains rich in BA are present in the MAA-BA chains. This statement can be supported by the results reported by Kulikov et al. [52], which show that the reactivity of MAA in emulsion polymerization is higher, by a factor of at least 4 , than the reactivity of BAA. In emulsion copolymerization, the initiation can be carried out in the aqueous phase, or inside the micelles. Thus, the solubility and concentration of the co-monomers play a key factor in defining the locus where initiation reactions are mainly developed. Since MAA is highly soluble in water, it is very probable that at low reaction times, MAA oligomers created in the aqueous phase react with $\mathrm{CNTs}_{\mathrm{o}-\mathrm{OCl}-\mathrm{MAA}}$ or $\mathrm{CNTs}_{\mathrm{r}-\mathrm{OCl}-\mathrm{MAA}}$. However, as the reaction time proceeds, the BA units react preferentially. This would explain how MAA-rich domains and BA-rich domains were formed. A homogeneous dispersion of $\mathrm{CNTs}_{\mathrm{o}-\mathrm{OCl}-\mathrm{MAA}}$ or $\mathrm{CNTs}_{\mathrm{r}-\mathrm{OCl}-\mathrm{MAA}}$ aids in carrying out this process performance. On the contrary, when the co-monomeric formulation is richer in MAA, both MAA and BA molecules react during the entire IEP process. In this situation, the formation of segregation domains rich in BA or MAA is more difficult. As a consequence, a random structure is formed in MAA-BA chains, which was 
detected by the appearance of a single glass transition temperature, as was detected in the DSC thermograms of Nano 1, Nano 5, Nano 6, and Nano 8.

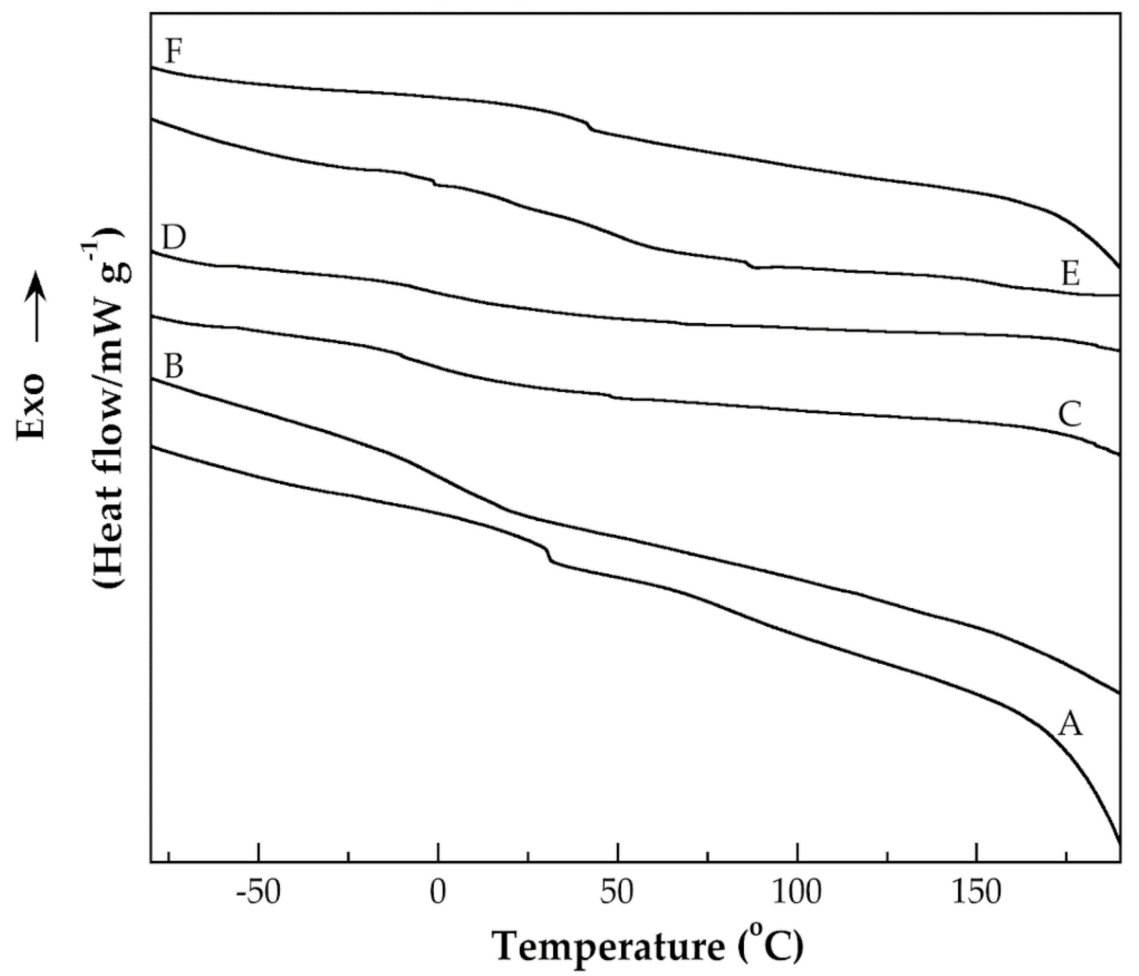

Figure 6. DSC thermograms of Mat 2 (A), Mat 1 (B), Nano 3 (C), Nano 4 (D), Nano 7 (E), and Nano 8 (F).

Table 4. Glass transition temperatures of the pure MAA-BA copolymers and the $\mathrm{CNTs}_{\mathrm{O}-\mathrm{OCl}-\mathrm{MAA}}-\mathrm{BA}$ or $\mathrm{CNTs}_{\mathrm{r}-\mathrm{OCl}-\mathrm{MAA}}-\mathrm{BA}$ nanocomposites.

\begin{tabular}{ccc}
\hline Code & $\begin{array}{c}\boldsymbol{T}_{\mathbf{g}} \mathbf{1} \\
(\mathbf{K})\end{array}$ & $\begin{array}{c}\boldsymbol{T}_{\mathbf{g}} \mathbf{2} \\
\text { (K) }\end{array}$ \\
\hline Mat 1 & 279.15 & - \\
\hline Mat 2 & 304.15 & - \\
\hline Nano 1 & 322.15 & - \\
\hline Nano 2 & 300.15 & 362.15 \\
\hline Nano 3 & 264.15 & 324.15 \\
\hline Nano 4 & 271.15 & 351.15 \\
\hline Nano 5 & 302.15 & - \\
\hline Nano 6 & 303.15 & 351.15 \\
\hline Nano 7 & 271.15 & - \\
\hline Nano 8 & 315.15 & \\
\hline
\end{tabular}

The morphology of the studied nanocomposites has crucial importance in their possible use as a drug delivery system sensitive to the medium $\mathrm{pH}$. In this sense, a particular drug can be preferentially adsorbed in their hydrophilic or hydrophobic domains and, as has been reported for other stimuli-responsive polymers, used as smart nano-carriers [53]. The $\mathrm{pH}$-responsive behavior of the MAA would facilitate the controlled delivery of drugs. This is highly desirable because different tissues and cells have varied $\mathrm{pH}$ values [54].

Figure 7 shows the hydrocortisone release profiles for pure MAA-BA copolymer Mat 2 and for the nanocomposites Nano 5 and Nano 6 obtained at pH 5. These nanocomposites, 
and their pure polymer matrix, were prepared with the same initial content of MAA (40 wt.\%) and in the same way, they have a random chemical structure. It is evident that the amount of hydrocortisone released from Nano 6 is higher than those observed for the other two materials. At $73 \mathrm{~h}$, Nano 6 releases $23 \%$ of hydrocortisone. These results contrast with the ones observed for Mat 2 and Nano 5. In this regard, the poor hydrocortisone release from Mat 2 indicates that this MAA-BA copolymer has little capability to act as a hydrocortisone carrier. These results mean that the type of $\mathrm{CNTs}_{\mathrm{f}}$ used to prepare the nanocomposites $\left(\mathrm{CNTs}_{\mathrm{o}}\right.$ for Nano 5 or $\mathrm{CNTs}_{\mathrm{r}}$ for Nano 6) has a crucial effect on the behavior of hydrocortisone release observed. In this regard, Table 3 shows that the ratios of $\mathrm{C}=\mathrm{O} / \mathrm{CH}_{3}$ signals, measured by ${ }^{13} \mathrm{C}-\mathrm{NMR}$ and $\mathrm{O}-\mathrm{C}=\mathrm{O} / \mathrm{C}-\mathrm{H}$ signals, evaluated by XPS, are higher for Nano 6 than Nano 5. These results also suggest that the content of $\mathrm{CNTs}_{\mathrm{r}}$ in Nano 6 is higher than the CNTs o content in Nano 5. Therefore, there is a direct relationship between the hydrocortisone release capability and the content of $\mathrm{CNTs}_{\mathrm{f}}$ in the polymer matrix of the nanocomposites studied. Our results confirm that it is possible to fill the internal cavity of CNTs with a drug to create drug reservoirs, as reported by Hampel et al., who used carboplatin as a filling drug of oxidized MWCNTs [55]. At $\mathrm{pH}$, the collapsed structure of PMAA starts to change because their carboxylic groups (completely self-associated by hydrogen bonds at $\mathrm{pH}<4$ ) now can be deprotonated. A change in the balance from inter-associated to self-associate hydrogen bonds can be the driving force to the release of hydrocortisone charged into the $\mathrm{CNTs}_{\mathrm{f}}$. With respect to the swelling degree of the nanocomposites and of their polymer matrix, after $48 \mathrm{~h}$ of the swell-test at $\mathrm{pH} 5$, the swelling could not be calculated. Two factors explain these results: (i) the nanocomposites and their polymeric matrix are mainly hydrophobic, and (ii) at $\mathrm{pH}$, the MAA units inserted in the two materials mentioned are self-associated by hydrogen bonding. This means that there is no interaction with water and, as a consequence, no swelling was detected.

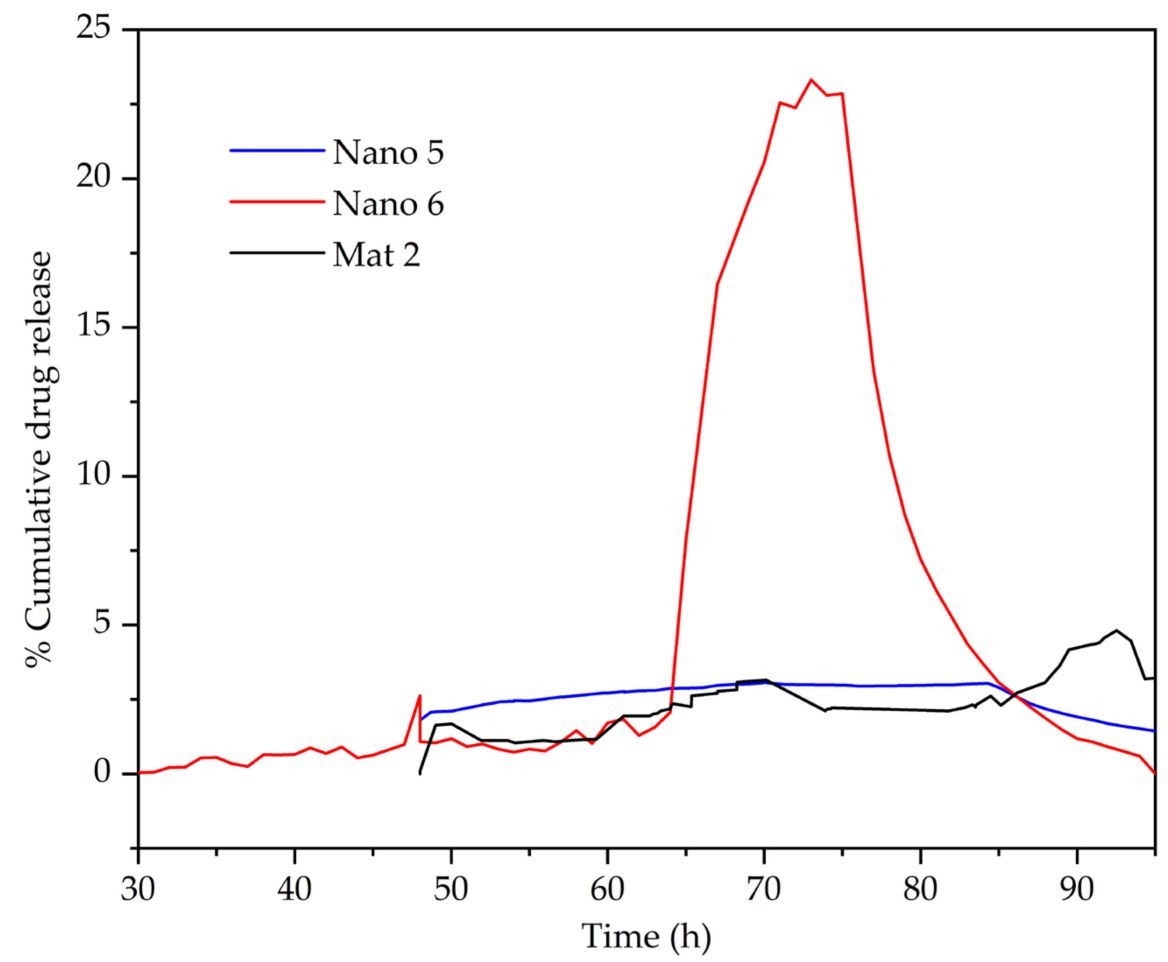

Figure 7. Hydrocortisone release profiles at $\mathrm{pH} 5$ for Mat 2, Nano 5, and Nano 6.

Figures 8 and 9 show FT-IR partial spectra centered in the range from 1570 to $1830 \mathrm{~cm}^{-1}$ for Mat 2 and Nano 6 samples, respectively. Spectra presented in Figures 8A and 9A correspond to purified Mat 2 and Nano 6, respectively, while spectra $8 \mathrm{~B}$ and $9 \mathrm{~B}$ are also of Mat 2 and Nano 6, respectively, but now after hydrocortisone release finished. Both spectra 
in each figure were normalized taking the absorbance of the most intense band as the unit. In this region, the spectral contributions due to the stretching vibration of carboxyl groups were resolved. It is evident the similarity between the peak spectral patterns shown on these figures. Thus, the Figures $8 \mathrm{~A}$ and $9 \mathrm{~A}$ spectra show that the most intense band was detected at $1733 \mathrm{~cm}^{-1}$ in the spectrum of Mat 2 and at $1729 \mathrm{~cm}^{-1}$ in the spectrum of Nano 6 , respectively. Stretching vibrations of carboxyl groups linked by inter-associated hydrogen bonding cause these spectral features [56]. For Mat 2, these hydrogen bonds are formed through an association between carbonyl groups, of BA and carboxyl groups of MAA, while for Nano 6, besides this association, the participation of free hydroxyl and carboxyl groups inserted on the walls of $\mathrm{CNTs}_{\mathrm{r}}$ to form hydrogen bonds must be considered. In this last case, formation of hydrogen bonds with either carbonyl groups of BA or carboxyl groups of MAA is possible. This spectral behavior is induced by the $\mathrm{pH}$ (close to 7). Due to the fact that hydrocortisone has three hydroxyl groups and two carbonyl groups, it is expected that these functional groups can form hydrogen bonds with the corresponding functional groups of Mat 2 and Nano 6. After the hydrocortisone release ended, the complex balance of inter-associated or self-associated hydrogen bonds has changed. The Figures $8 \mathrm{~B}$ and $9 \mathrm{~B}$ spectra show that now the most intense band was detected at $1700 \mathrm{~cm}^{-1}$ (Figure $8 \mathrm{~B}$ ) or at $1703 \mathrm{~cm}^{-1}$ (Figure 9B). Stretching vibrations of self-associated carboxyl groups linked by hydrogen bonds forming dimers that caused these bands [57]. This result means that now prevalence of hydrogen bonds by self-association over inter-association is occurring. Therefore, we consider that the behavior observed in the hydrocortisone release profile of Nano 6 is caused by the change in the balance of carboxyl groups (both in MAA units and in $\mathrm{CNTs}_{\mathrm{r}}$ ) inter-associated with respect to self-associated by hydrogen bonds. In other words, the breaking of the hydrogen bonds, that kept it physically attached to the $\mathrm{CNTs}_{\mathrm{r}}$, drives the release of hydrocortisone. This is due to the influence that $\mathrm{pH}$ has on the amount and nature of the hydrogen bonds formed by carboxylic acid groups.

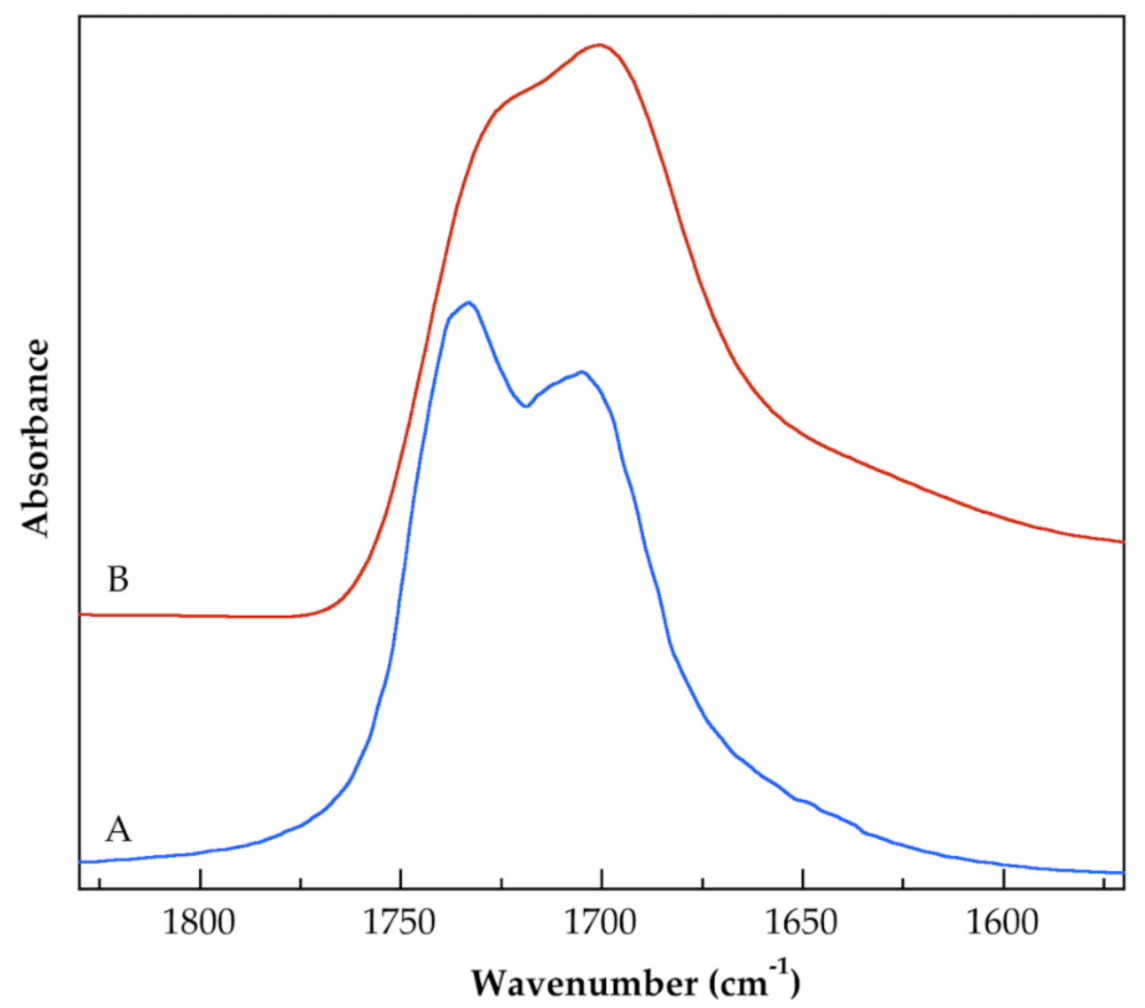

Figure 8. Partial FT-IR spectra in the $1570-1830 \mathrm{~cm}^{-1}$ region of the purified Mat 2 (A) and of the Mat 2 after hydrocortisone release finished (B). 


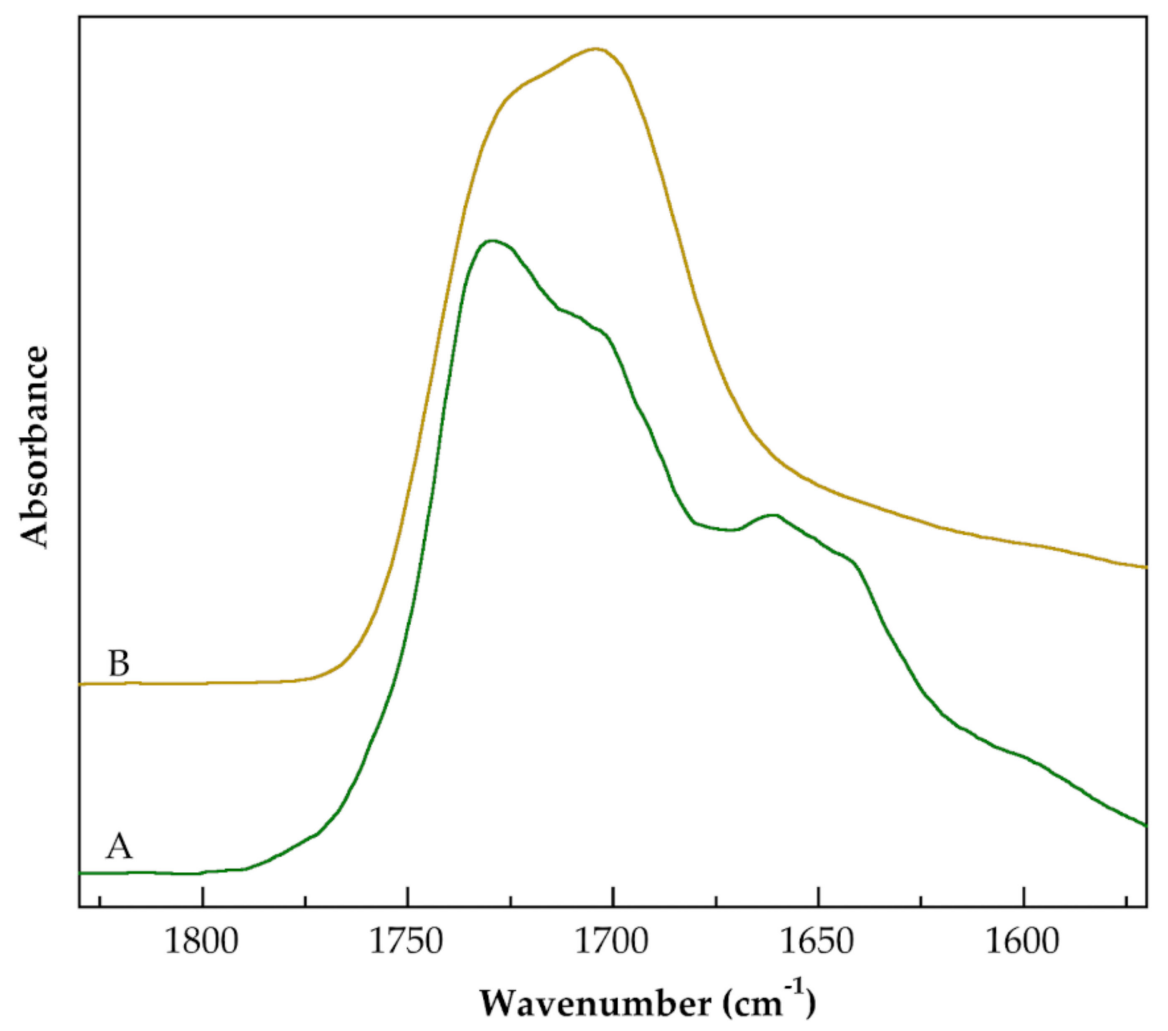

Figure 9. Partial FT-IR spectra centered in $1570-1830 \mathrm{~cm}^{-1}$ region of the purified Nano 6 (A) and of the Nano 6 at the end of hydrocortisone release (B).

For nanocomposites and MAA-BA copolymer (Mat 1) prepared from an initial formulation richest in $\mathrm{BA}$, we did not obtain adequate specimens to make an appropriate hydrocortisone release study.

The other possibility for hydrocortisone release is the hydrolysis of anhydride groups (very sensitive to $\mathrm{pH}$ ) [58] is ruled out, at least at $\mathrm{pH} 5$, because there is no evidence of hydrolysis in the FT-IR spectra of the series of nanocomposites synthesized.

\section{Conclusions}

In this work, a smart drug delivery system was synthesized successfully. This system consists of nanocomposites of $\mathrm{CNTs}_{\mathrm{o}-\mathrm{OCl}-\mathrm{MAA}}-\mathrm{BA}$ and $\mathrm{CNTs}_{\mathrm{r}-\mathrm{OCl}-\mathrm{MAA}}-\mathrm{BA}$ that were synthesized by IEP. An analysis of FE-SEM and HR-TEM microscopies made it possible to observe that the CNTs synthesized by CVD have a structure of HMWCNTs. To achieve the synthesis of the aforementioned nanocomposites, HMWCNTs were previously functionalized chemically to attach the acyl chloride functionality onto their walls. This reactive functional group of the $\mathrm{CNTs}_{\mathrm{o}-\mathrm{OCl}}$ and $\mathrm{CNTs}_{\mathrm{r}-\mathrm{OCl}}$ reacted with the hydroxyl group of the methacrylic acid, creating an anhydride group, but keeping the $\mathrm{C}=\mathrm{C}$ bond unchanged. Through radical polymerization of MAA and BA monomers on the substrate ( $\mathrm{CNTs}_{\mathrm{o}-\mathrm{OCl}-\mathrm{MAA}}$ or $\left.\mathrm{CNTs}_{\mathrm{r}-\mathrm{OCl}-\mathrm{MAA}}\right)$, $\mathrm{CNTs}_{\mathrm{o}-\mathrm{OCl}-\mathrm{MAA}}-\mathrm{BA}$ and $\mathrm{CNTs}_{\mathrm{r}-\mathrm{OCl}-\mathrm{MAA}}-\mathrm{BA}$ nanocomposites were synthesized. Raman and FT-IR spectroscopies confirmed that the functionalization of the purified CNTs was carried out as shown in Scheme 1. XPS and ${ }^{13} \mathrm{C}-\mathrm{NRM}$ spectroscopies show that the MAABA chains are attached to $\mathrm{CNTs}_{\mathrm{O}-\mathrm{OCl}-\mathrm{MAA}}$ or $\mathrm{CNTs}_{\mathrm{r}-\mathrm{OCl} \text {-MAA }}$ substrates. DSC thermograms evidenced that the co-monomer formulation and the amount of $\mathrm{CNTs}_{\mathrm{o}-\mathrm{OCl}}$ or $\mathrm{CNTs}_{\mathrm{r}-\mathrm{OCl}}$ used in the nanocomposites preparation determine the morphology of the synthesized nanocomposites. In general, nanocomposites synthesized with a higher amount of BA show two glass transition temperatures, while nanocomposites prepared with a higher amount of MAA show one glass transition temperature. There is no evidence that nanocomposites morphology influences their ability to release hydrocortisone. In the synthesized nanocomposites the $\mathrm{CNTs}_{\mathrm{f}}$, incorporated in their structure, act as hydrocortisone reservoirs. 
Of the all nanocomposites studied, Nano 6 shows the best ability to release hydrocortisone. The hydrocortisone release of Nano 6 carried out at $\mathrm{pH} 5$ starts after $73 \mathrm{~h}$ after having initiated the release test at room temperature. The hydrocortisone release profile that shows the Nano 6 is driven by a change in the inter-associated to self-associated hydrogen bonds balance. The polymeric pure matrix of the synthesized nanocomposites does not show a significant ability to release hydrocortisone. Therefore, the presence of the $\mathrm{CNTs}_{\mathrm{r}}$ in the Nano 6 plays a crucial role in obtaining a smart drug delivery system.

Although the prepared nanocomposites in this work have a convenient ability to release hydrocortisone, the decisive role that the functionalized CNTs have in the drug delivery performance of nanocomposites urges the necessity to evaluate CNTs' toxicity. The unresolved problem of toxicity of the CNTs must be overcome before their practical use can be explored. The toxicity of the CNTs is a risk that limit the possible use of the nanocomposites studied. This risk must be thoroughly evaluated to avoid undesirable health problems. Therefore, the possible impact of the studied nanocomposites on human health, by their use in a drug delivery system at $\mathrm{pH} 5$, depends upon their evaluation as a potential threat to living tissues.

Supplementary Materials: The following are available online at https:/ / www.mdpi.com/2073-436 0/13/4/533/s1, Figure S1: The 1H-NMR spectrum of the Mat 2.

Author Contributions: Conceptualization, F.L.-S. and S.M.N.-D.; methodology, J.A.T.-Á., F.A.L.-D. and L.R.C.-Z.; validation, S.M.N.-D., A.M.-R. and F.L.-S.; formal analysis, J.A.T.-Á., L.R.C.-Z., M.V.L. and K.A.B.-R.; investigation, J.A.T.-Á.; resources, A.M.-R., F.L.-S. and S.M.N.-D.; data curation, L.R.C.-Z.; writing — original draft preparation, S.M.N.-D.; writing—review and editing, K.A.B.-R., F.L.-S., A.M.-R. and S.M.N.-D.; visualization, J.A.T.-Á. and L.R.C.-Z.; supervision, S.M.N.-D.; project administration, F.L.-S. and S.M.N.-D.; funding acquisition, A.M.-R., F.L-S. and S.M.N.-D. All authors have read and agreed to the published version of the manuscript.

Funding: This research was funded by Consejo Nacional de Ciencia y Tecnología (CONACyT), grant number 123732 and 101369. Also, the research was funded by Universidad Nacional Autónoma de México (UNAM), grant number DGAPA-PAPIIT-IN114018 and PAIP-FQ 5000-9080.

Institutional Review Board Statement: Not applicable.

Informed Consent Statement: Not applicable.

Data Availability Statement: The data presented in this study are available on request from the corresponding author.

Acknowledgments: The authors are indebted to Engr. Francisco Rodríguez Melgarejo (CINVESTAV, Unidad Querétaro) for obtaining the Raman spectra. Also, the authors kindly acknowledge The National Laboratory for Characterization of Physicochemical Properties and Molecular structure UG for NMR studies.

Conflicts of Interest: The authors declare no conflict of interest. The funders had no role in the design of the study; in the collection, analyses, or interpretation of data; in the writing of the manuscript, or in the decision to publish the results.

\section{References}

1. Feldman, D. Polymer Nanocomposites in medicine. J. Macromol. Sci. Part A 2016, 53, 55-62. [CrossRef]

2. Chaurasia, A.; Suzhu, Y.; Henry, C.K.F.; Mogal, V.T.; Saha, S. Properties and Applications of Polymer Nanocomposites. In Handbook of Manufacturing Engineering and Technology, 1st ed.; Nee, A.Y.C., Ed.; Springer-Verlag: London, UK, 2015; pp. $43-98$.

3. Khan, M.U.; Gomes, V.G.; Altarawneh, I.S. Synthesizing polystyrene/carbon nanotube composites by emulsion polymerization with non-covalent and covalent functionalization. Carbon 2010, 48, 2925-2933. [CrossRef]

4. Ma, P.-C.; Siddiqui, N.A.; Marom, G.; Kim, J.-K. Dispersion and functionalization of carbon nanotubes for polymer-based Nanocomposites: A review. Compos. Part A 2010, 41, 1345-1367. [CrossRef]

5. Jeon, I.-Y.; Chang, D.W.; Nanjundan, A.K.; Baek, J.-B. Functionalization of carbon nanotubes. In Carbon Nanotubes Polymer Nanocomposites, 1st ed.; Yellampalli, S., Ed.; Intech: Rijeka, Croatia, 2011; pp. 91-110.

6. Adeli, M.; Bahari, A.; Hekmatara, H. Carbon nanotube-graft-poly(citric acid) nanocomposites. NANO 2008, 3, 37-44. [CrossRef]

7. Saeed, K.; Park, S.-Y.; Haider, S.; Baek, J.-B. In situ polymerization of multi-walled carbon nanotube/nylon-6 nanocomposites and their electrospun nanofibers. Nanoscale Res. Lett. 2009, 4, 39-46. [CrossRef] 
8. Xia, H.; Wang, Q.; Qiu, G. Polymer-encapsulated carbon nanotubes prepared through ultrasonically initiated in situ emulsion polymerization. Chem. Mater. 2003, 15, 3879-3886. [CrossRef]

9. Xia, H.; Qiu, G.; Wang, Q. Polymer/carbon nanotube composite emulsion prepared through ultrasonically assisted in situ emulsion polymerization. J. Appl. Polym. Sci. 2006, 100, 3123-3130. [CrossRef]

10. Mittal, V. Polymer Nanocomposites in emulsion and suspension: An overview. In Polymer Nanocomposites by Emulsion and Suspension Polymerization, 1st ed.; Mittal, V., Ed.; Royal Society of Chemistry: London, UK, 2011; pp. 1-31.

11. Khan, M.U.; Reddy, K.R.; Snguanwongchai, T.; Haque, E.; Gomes, V.G. Polymer brush synthesis on surface modified carbon nanotubes via in situ emulsion polymerization. Colloid. Polym. Sci. 2016, 294, 1599-1610. [CrossRef]

12. Massoumi, B.; Ramezani, M.; Jaymand, M.; Ahmadinejad, M. Multi-walled carbon nanotubes-g-[poly(ethylene glycol)-b-poly(ecaprolactone)]: Synthesis, characterization, and properties. J. Polym. Res. 2015, 22, 214. [CrossRef]

13. Du, W.; Slany, M.; Wang, X.; Chen, G.; Zhang, J. The inhibition property and mechanism of a novel low molecular weight zwitterionic copolymer for improving wellbore stability. Polymers 2020, 12, 708. [CrossRef]

14. Lowman, A.M.; Peppas, N.A. Molecular analysis of interpolymer complexation in graft copolymer networks. Polymer 2000, 41, 73-80. [CrossRef]

15. Thakral, S.; Thakral, N.K.; Majumdar, D.K. Eudragit ${ }^{\circledR}$ : A technology evaluation. Expert. Opin. Drug. Deliv. 2013, 10, 131-149. [CrossRef] [PubMed]

16. Cui, J.; Kratz, K.; Hiebl, B.; Jung, F.; Lendlein, A. Soft poly(n-butyl acrylate) networks with tailored mechanical properties designed as substrates for in vitro models. Polym. Adv. Technol. 2011, 22, 126-132. [CrossRef]

17. Guo, L.; Jiang, Y.; Chen, S.; Qiu, T.; Li, X. Self-assembly of poly(methacrylic acid)-b-poly(butyl acrylate) amphiphilic block copolymers in methanol via RAFT polymerization and during film formation for wrinkly surface pattern. Macromolecules 2014, 47, 165-174. [CrossRef]

18. Peng, Y.; Chen, L.; Ye, S.; Kang, Y.; Liu, J.; Zeng, S.; Yu, L. Research and development of drug delivery systems based on drug transporter and nano-formulation. Asian J. Pharm. Sci. 2020, 15, 220-236. [CrossRef]

19. Kumar, N.A.; Ganapathy, H.S.; Kim, J.S.; Jeong, Y.S.; Jeong, Y.T. Preparation of poly 2-hydroxyethyl methacrylate functionalized carbon nanotubes as novel biomaterial nanocomposites. Eur. Polym. J. 2008, 44, 579-586. [CrossRef]

20. Boyles, M.S.P.; Young, L.; Brown, D.M.; MacCalman, L.; Cowie, H.; Moisala, A.; Smail, F.; Smith, P.J.W.; Proudfoot, L.; Windle, A.H.; et al. Multi-walled carbon nanotube induced frustrated phagocytosis conditions in macrophages are length dependent and greater than that of asbestos. Toxicol. Vitro 2015, 29, 1513-1528. [CrossRef]

21. Rahman, L.; Jacobsen, N.R.; Aziz, S.A.; Wu, D.; Williams, A.; Yauk, C.L.; White, P.; Wallin, H.; Vogel, U.; Halappanavar, S. Multiwalled carbon nanotube-induced genotoxic, inflammatory and pro-fibrotic responses in mice: Investigating the mechanisms of pulmonary carcinogenesis. Mutat. Res. 2017, 823, 28-44. [CrossRef]

22. Jafar, A.; Alshatti, Y.; Ahmad, A. Carbon nanotube toxicity: The smallest biggest debate in medical care. Cogent Med. 2016, 3, 1217970. [CrossRef]

23. Fisher, C.; Rider, A.E.; Han, Z.J.; Kumar, S.; Levchenko, I.; Ostrikov, K. Applications and nanotoxicity of carbon nanotubes and graphene in biomedicine. J. Nanomater. 2012, 2012, 315185. [CrossRef]

24. Holmes, P.F.; Bohrer, M.; Kohn, J. Exploration of polymethacrylate structure-property correlations: Advances towards combinatorial and high-throughput methods for biomaterials discovery. Prog. Polym. Sci. 2008, 33, 787-796. [CrossRef] [PubMed]

25. Mastropietro, D.; Park, K.; Omidian, H. Polymers in oral drug delivery. In Comprehensive Biomaterials II, 1st ed.; Ducheyne, P., Healy, K., Hutmacher, D.W., Grainger, D.W., Kirkpatrick, C.J., Eds.; Elsevier: Amsterdam, The Netherlands, 2017; Volume 4, pp. $430-444$.

26. Barrera-Rivera, K.A.; Martínez-Richa, A. L-Lysine-modified poly(ester-urethane) based on polycaprolactone for controlled release of hydrocortisone. In Green Polymer Chemistry: New Products, Processes, and Applications, 1st ed.; Cheng, H.N., Gross, R.A., Smith, P.B., Eds.; ACS Symposium Series 1310; American Chemical Society: Washington, DC, USA, 2018; pp. $163-175$.

27. Weigel, M.; Hahnert, S.; Sherlock, M.; Agha, A.; Behan, L.A.; Stewart, P.M.; Arlt, W.; Beier, D.; Freyt, K.; Zopf, K.; et al. Immediate versus modified release hydrocortisone in mitotane-treated patients with adrenocortical cancer. Clin. Endocrinol. 2017, 86, 499-505. [CrossRef]

28. Dorff, T.B.; Crawford, E.D. Management and challenges of corticosteroid therapy in men with metastatic castrate-resistant prostate cancer. Ann. Oncol. 2013, 24, 31-38. [CrossRef] [PubMed]

29. Warris, L.T.; van den Heuvel-Eibrink, M.M.; Aarsen, F.K.; Pluijm, S.M.F.; Bierings, M.B.; van den Bos, C.; Zwaan, C.M.; Thygesen, H.H.; Tissing, W.J.E.; Veening, M.A.; et al. Hydrocortisone as an intervention for dexamethasone-induced adverse effects in pediatric patients with acute lymphoblastic leukemia: Results of a double-blind, randomized controlled trial. J. Clin. Oncol. 2016, 34, 2287-2293. [CrossRef]

30. Das, A.; Kundu, R.; Agarwal, R.; Ghose, A. CNS Prophylaxis in diffuse large B cell Lymphoma. J. Cancer Prev. Curr. Res. 2016, 5, 00177. [CrossRef]

31. Rúan-Esparza, L.; Soto, V.; Gómez-Salazar, S.; Rabelero, M.; Ávalos-Borja, M.; Luna-Bárcenas, G.; Prokhorov, E.; Nuño-Donlucas, S.M. Poly[ethylene-co-(acrylic acid)]-based nanocomposites: Thermal and mechanical properties and their structural characteristics studied by Raman spectroscopy. Polym. Compos. 2011, 32, 1181-1189. [CrossRef]

32. Xia, R.; Li, M.; Zhang, Y.; Qian, J.; Yuan, X. Surface modification of MWNTs with BA-MMA-GMA terpolymer by single-step grafting technique. J. Appl. Polym. Sci. 2011, 119, 282-289. [CrossRef] 
33. Taklimi, S.R.; Ghazinezami, A.; Askari, D. Chemical functionalization of helical carbon nanotubes: Influence of sonication time and concentration of sulfuric and nitric acids with 3:1 mixing ratio. J. Nanomater. 2019, 2019, 2836372. [CrossRef]

34. Taklimi, S.R. Effects of Different Processing Parameters on Covalent Functionalization of Straight and Helical Carbon Nanotubes for Nanocomposite Applications. Ph.D. Thesis, Wichita State University, Wichita, KS, USA, 2017.

35. Shen, Q.; Liu, M.; Lü, Y.; Zhang, D.; Cheng, Z.; Liu, Y.; Gao, H.; Jin, Z. Label-free electrochemical immunosensor based on a functionalized ionic liquid and helical carbon nanotubes for the determination of cardiac troponin I. ACS Omega 2019, 4, 11888-11892. [CrossRef]

36. Tang, N.; Wen, J.; Zhang, Y.; Liu, F.; Lin, K.; Du, Y. Helical carbon nanotubes: Catalytic particle size-dependent growth and magnetic properties. ACS Nano 2010, 4, 241-250. [CrossRef] [PubMed]

37. Paszkiewicz, M.; Sikorska, C.; Leszczynska, D.; Stepnowski, P. Helical multi-walled carbon nanotubes as an efficient material for the dispersive solid-phase extraction of low and high molecular weight polycyclic aromatic hydrocarbons from water samples: Theoretical study. Water Air Soil Pollut. 2018, 229, 253. [CrossRef] [PubMed]

38. Pelletier, M.J. Raman scattering in carbon materials. In Analytical Applications of Raman Spectroscopy, 1st ed.; Wiley-Blackwell Science: Malden, MA, USA, 1999; pp. 367-431.

39. Chen, G.; Bandow, S.; Margine, E.R.; Nisoli, C.; Kolmogorov, A.N.; Crespi, V.H.; Gupta, R.; Sumanasekera, G.U.; Iijima, S.; Eklund, P.C. Chemically doped double-walled carbon nanotubes: Cylindrical molecular capacitors. Phys. Rev. Lett. $2003,90,257403$. [CrossRef] [PubMed]

40. Costa, S.; Borowiak-Palen, E. Raman study on doped multiwalled carbon nanotubes. Acta Phys. Pol. A 2009, 116, 32-35. [CrossRef]

41. Thomsen, C.; Reich, S. Double resonant Raman scattering in graphite. Phys. Rev. Lett. 2000, 85, 5214. [CrossRef]

42. Slany, M.; Jankovic, L.; Madejova, J. Structural characterization of organo-montmorillonites prepared from a series of primary salts: Mid-IR and near-IR study. App. Clay Sci. 2019, 176, 11-20. [CrossRef]

43. Iizuka, Y.; Yamamoto, Y.; Kawahara, S. Latex-state ${ }^{13}$ C-NMR spectroscopy for poly(butyl acrylate). Colloid Polym. Sci. 2019, 297, 133-139. [CrossRef]

44. Andrew, E.R.; Eades, R.G. Possibilities for high-resolution nuclear magnetic resonance spectra of crystals. Discuss. Faraday Soc. 1962, 34, 38-42. [CrossRef]

45. Koenig, J.L. Spectroscopy of Polymers, 2nd ed.; Elsevier: New York, NY, USA, 1999; p. 368.

46. Herrera-Gómez, A.; Bravo-Sánchez, M.; Ceballos-Sánchez, O.; Vázquez-Lepe, M.O. Practical methods for background substraction in photoemission spectra. Surf. Interface Anal. 2014, 46, 897-905. [CrossRef]

47. Ratner, B.D.; Castner, D.G. Electron spectroscopy for chemical analysis. In Surface Analysis: The Principal Techniques, 2nd ed.; Vickerman, J.C., Gilmore, I.S., Eds.; Wiley: Chichester, UK, 2009; pp. 53-79.

48. Beamson, G.; Briggs, D. High Resolution XPS of Organic Polymers: The Scienta ESCA300 Database, 1st ed.; Wiley: Chichester, UK, 1992; pp. 110-117.

49. Montalbetti, C.A.G.N.; Falque, V. Amide bond formation and peptide coupling. Tetrahedron 2005, 61, 10827-10852. [CrossRef]

50. Zhang, X.; Takegoshi, K.; Hikichi, K. Phase separation and thermal degradation of poly(vinyl alcohol)/poly(methacrylic acid) and poly(vinyl alcohol)/poly(acrylic acid) systemas by ${ }^{13}$ C c.p./m.a.s. n.m.r. Polymer 1992, 33, 718-724. [CrossRef]

51. Fernández-García, M.; Cuervo-Rodríguez, R.; Madruga, E.L. Glass transition of butyl acrylate-methyl methacrylate copolymers. J. Polym. Sci. Part B Polym. Phys. 1999, 37, 2512-2520. [CrossRef]

52. Kulikov, S.A.; Yablokova, N.V.; Nikolayeva, T.V.; Aleksandrov, Y.A. Emulsion copolymerization of butyl acrylate with methacrylic acid. Polym. Sci. USSR 1989, 31, 2542-2548. [CrossRef]

53. Sang, X.; Yang, Q.; Shi, G.; Zhang, L.; Wang, D.; Ni, C. Preparation of $\mathrm{pH} /$ redox dual responsive polymeric micelles with enhanced stability and drug controlled release. Mater. Sci. Eng. C 2018, 91,727-733. [CrossRef]

54. Zhang, L.; Ding, Y.; Wen, Q.; Ni, C. Synthesis of core-crosslinked zwitterionic polymer nano aggregates and pH/Redox responsiveness in drug controlled release. Mater. Sci. Eng. C 2020, 106, 110288. [CrossRef]

55. Hampel, S.; Kunze, D.; Haase, D.; Krämer, K.; Rauschenbach, M.; Ritschel, M.; Leonhardt, A.; Thomas, J.; Oswald, S.; Hoffmann, V.; et al. Carbon nanotubes filled with a chemotherapeutic agent: A nanocarrier mediates inhibition of tumor cell growth. Nanomedicine 2008, 3, 175-182. [CrossRef] [PubMed]

56. Lee, J.Y.; Painter, P.C.; Coleman, M.M. Hydrogen bonding in polymer blends. 3. Blends involving polymers containing methacrylic acid and ether groups. Macromolecules 1988, 21, 346-354. [CrossRef]

57. Katime, I.; Parada, L.; Meaurio, E.; Cesteros, L. Recent research developments in hydrogen bonding in polymer blends by Fourier transform infrared spectroscopy (FTIR) and calorimetry. Recent Res. Devel. Polym. Sci. 1997, 1, 91-107.

58. Andrés, G.O.; Granados, A.M.; de Rossi, R.H. Kinetic study of the hydrolysis of phthalic anhydride and aryl hydrogen phthalates. J. Org. Chem. 2001, 66, 7653-7657. [CrossRef] [PubMed] 